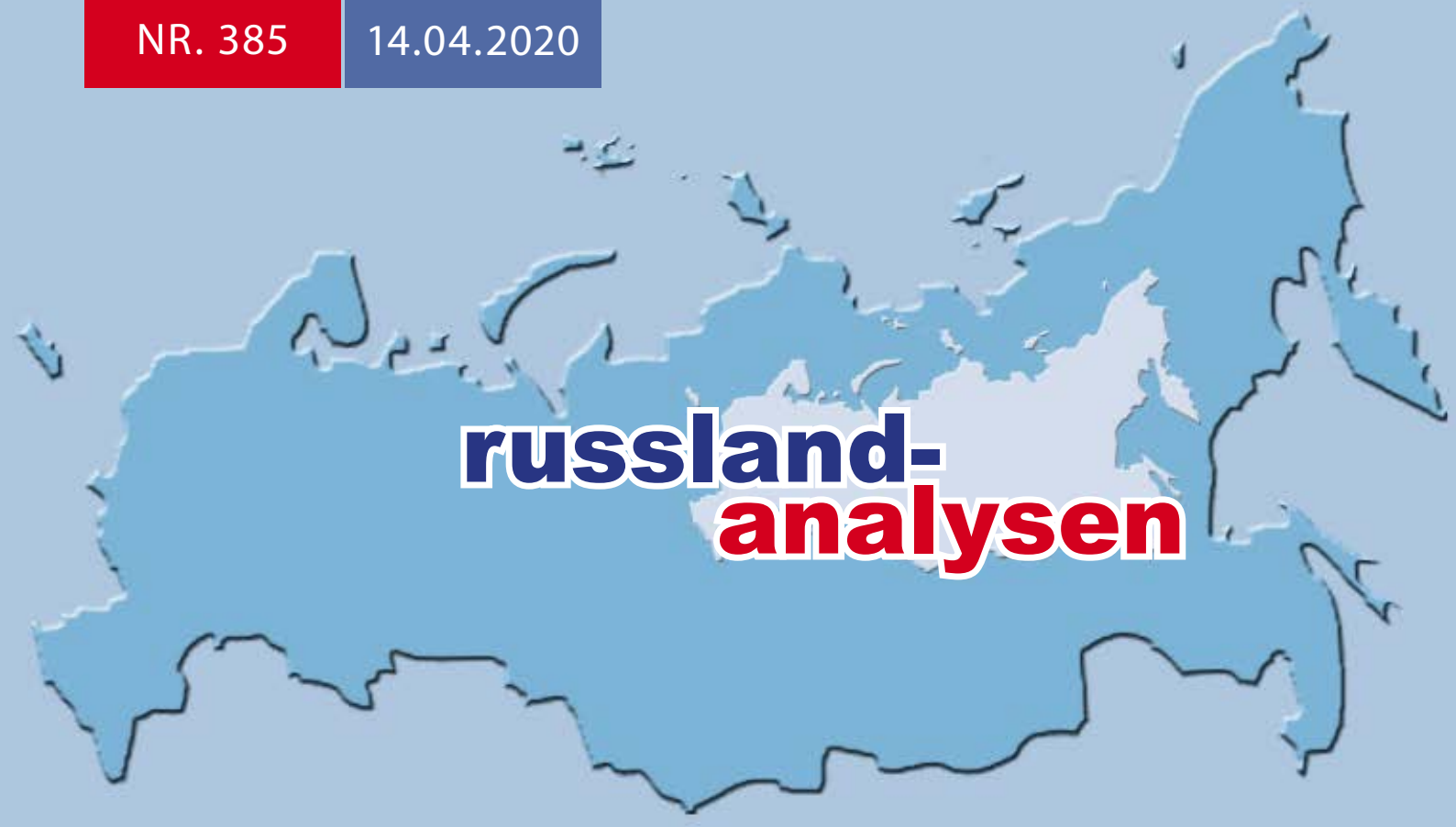

\title{
http://www.laender-analysen.de/russland/
}

\section{COVID-19 IN RUSSLAND}

- EDITORIAL

Vorwort zu dieser Ausgabe der Russland-Analysen

- ANALYSE

Russlands Gesundheitssystem und das Coronavirus

Judy Twigg (Virginia Commonwealth University)

ANALYSE

Digitalisierung des Gesundheitswesens: Stand und Perspektiven von

eHealth und Telemedizin in Russland

Philipp Walther (Hochschule Fresenius)

\section{- NOTIZEN AUS MOSKAU}

Russland und Corona

Jens Siegert (Moskau)

STATISTIK

Covid-19 in Russland

CHRONIK

Covid-19-Chronik, 30. Januar - 29. März 2020

UMFRAGE

Coronavirus-Pandemie (20.-26 Februar und 19.-25. März 2020)

DEKODER

Das Corona-Virus im Vorlauf

Sergej Medwedew (Moskau)

DEKODER

Die Seuche, Igor Setschin und Allahs Wille

Wladislaw Inosemzew, Irina Tumakowa (Novaya Gazeta)

\section{CHRONIK}

Deutsche Gesellschaft für Osteuropakunde

\section{DGO}

Deutsches

Polen-Institut

\section{DEUTSCHES \\ POLEN}

INSTITUT
Forschungsstelle Osteuropa

an der Universität Bremen

Leibniz-Institut für

Agrarentwicklung in Transformationsökonomien

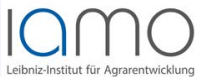

Leibniz-Institut für st- und Südosteuropaforschung

Zentrum für Osteuropa- und internationale Studien (ZOiS) $\mathrm{gGmbH}$ 


\section{Vorwort zu dieser Ausgabe der Russland-Analysen}

Die Russland-Analysen möchten durch Einbeziehung wissenschaftlicher Kompetenz und umfangreiche Dokumentationen komplexe Zusammenhänge aufzeigen. Dabei möchten sie über journalistische Berichterstattung hinausgehen, dieser aber gerade auch mit Bezug auf die Aktualität keine Konkurrenz machen. Dies zeigt sich insbesondere bei so dynamischen Entwicklungen wie der aktuellen Covid-19-Pandemie. Wenn Sie diese Ausgabe lesen, dürften einige Textstellen bereits überholt wirken. Wir bitten Sie daher, das Erscheinungsdatum zu berücksichtigen. Wir hoffen, dass die zentralen Aussagen, Analysen und Daten, die wir zusammengestellt haben, auch längerfristig von Relevanz und Interesse bleiben.

Der Themenschwerpunkt zur COVID-19-Pandemie ist erstellt worden durch das Teilprojekt B06 »Externe Reformmodelle und interne Debatten bei der Neukonzipierung von Sozialpolitik in der post-sowjetischen Region« des SFB 1342 "Globale Entwicklungsdynamiken von Sozialpolitik» (finanziell gefördert von der Deutschen Forschungsgemeinschaft).

Die Redaktion der Russland-Analysen

ANALYSE

\section{Russlands Gesundheitssystem und das Coronavirus}

Judy Twigg (Virginia Commonwealth University)

\section{Zusammenfassung}

Obwohl Russland im internationalen Vergleich bei der Bewältigung der Coronavirus-Pandemie recht moderate Fallzahlen von Covid-19-Erkrankten aufweist, sind die tatsächlichen Herausforderungen, die das Land zu bewältigen hat, enorm. Der Umgang mit den Fallzahlen, das Vorgehen zur Eindämmung des Virus und die Beschaffenheit des Gesundheitswesens lassen hier ernsthaft an der Effizienz der so sehr gepriesenen Vertikale der Macht zweifeln.

\section{Schlechte Zahlen}

Hinsichtlich des Coronavirus steht Russland, verglichen mit anderen Ländern, derzeit vor eher geringeren Herausforderungen. Die Regierung hat den ersten bestätigten Fall am 2. März vermeldet, und am 15. März den ersten Fall, dass sich das Virus ohne nachvollziehbare Einschleppung in einer Region verbreitet. Mit Stand vom 5. April haben sich den Angaben zufolge 5.400 Russen infiziert, bei fast 700.000 Tests, die vorgenommen wurden. Die Zahl der täglich gemeldeten Neuinfektionen hatte sich in der vergangenen Woche auf einem festen Niveau eingependelt. Die Epidemie scheint in Russland relativ viele junge Menschen zu treffen: 80 Prozent der bestätigten Infizierten sind zwischen 18 und 60 Jahren alt (Stand: 5. April).

Gegenüber den vermeldeten Zahlen sind allerdings viele Vorbehalte angebracht. Es ist unklar, welche Qualität und Reichweite die Tests haben. Es gibt viele individuelle Berichte, dass Menschen, die mit einer
Lungenentzündung oder anderen schweren Atemwegsproblemen ins Krankenhaus kamen und, nicht auf das Virus getestet wurden, obwohl die Symptome klar auf eine mögliche Infektion hinweisen. Die tatsächliche Zahl der Covid-19-Fälle in Russland ist sicherlich höher als die offiziell vermeldete. Das bestehende System der Anreize in der russischen Bürokratie führt dazu, dass Beamte auf der Ebene der lokalen Verwaltung oder der Gesundheitseinrichtungen besser keine schlechten Nachrichten überbringen sollten. Viele Krankenhausdirektoren erfahren jetzt sehr widersprüchliche Impulse: Sie verlangen ganz dringend nach zusätzlichen Ressourcen, um die bestehenden oder potenzielle Covid-19 Fallzahlen bewältigen zu können. Andererseits wollen sie auch nicht negativ auf sich aufmerksam machen. In diesem Zusammenhang war die Videokonferenz von Putin und den Gouverneuren der Regionen durch ihre Signale etwas Außerordentliches. Putin betonte mehrfach, wie wichtig es sei, dass diese seine Untergebenen 
ihm die Wahrheit sagen, ihn mit realen Daten versorgen und die Anweisungen befolgen. Putin hätte dies nicht so eindringlich betont, wenn die Realität, also die Art, in der die Dinge üblicherweise funktionieren, anders wäre: Untergebene lügen immer wieder darüber, wie die Lage vor Ort ist und wie sie diese zu bewältigen gedenken. Ein wirksames Vorgehen gegen eine Epidemie verlangt umfassende und genaue Daten sowie ein striktes Befolgen der gesundheitstechnischen Vorgaben, die aufgrund dieser Informationen formuliert wurden. Das Ausmaß an Verschleierung, Misstrauen und Tatenlosigkeit innerhalb des Systems in Russland, das sich hieraus ergibt, wirft die ernste Frage auf, inwieweit die viel gepriesene "Machtvertikale« in dieser Situation effizient ist.

\section{Die Ausbreitung (eindämmen)}

Mit Stand vom 5. April lag die größte Last an Covid19-Fällen wenig überraschend auf den größten städtischen Ballungsräumen, auf Moskau und dem Moskauer Gebiet sowie St. Petersburg und dem Leningrader Gebiet. Auch aus anderen Regionen werden kleinere lokale Ausbrüche vermeldet, so aus der Republik Komi, Nischnyj Nowgorod, dem Swerdlowsker Gebiet und Krasnodar. Die Fälle in der Republik Komi sollen auf einen Arzt eines städtischen Krankenhauses zurückzuführen sein, der vor Kurzem nach Europa gereist war (oder dessen Kinder gereist waren). Ein frei zugängliches Modell, das Daten des Reiseportals "tutu.ru« verwendet, besagt auf der Basis der Bewegungen von Flugzeug-, Bahn- und Buspassagieren im April 2020, dass die Epidemie in vielen russischen Städten mindestens bis zum September andauern wird. Die große Zahl weitläufiger urbaner Gebiete und dünnbesiedelter Gebiete in Russland erleichtert die Aufgabe einer physischen Distanzierung, falls die richtige Politik verfolgt und rechtzeitig durchgesetzt wird. Das hochgradig zentralisierte Verkehrssystem - bei dem die Hälfte aller Flüge über die fünf Städte Moskau, St. Petersburg, Krasnodar, Simferopol und Sotschi gehen - konzentriert viele Passagiere an relativ wenigen Orten (was die Verbreitung des Virus begünstigt); es erleichtert aber auch ein schnelles Eingreifen, um die Ausbreitung der Krankheit zu stoppen. Die zentralisierten Verkehrsströme machen wie überall die Bewohner großer Städte verwundbarer gegenüber der Epidemie.

Die Hauptstadt Moskau hat erst kürzlich weitgehende Abstandsgebote erlassen, die zu einem Abflachen der Ausbreitungskurve führen sollen. Es gab früh Berichte, dass eine Abschottung Moskaus von anderen Landesteilen diskutiert wird. Es ist aber unklar, ob Russland die nötigen personellen Ressourcen hat, um eine solche Maßnahme durchzusetzen. Die Republik Tschetschenien, die von Anfang an ihren eigenen, strikten Kurs gegen die Pandemie gefahren ist, war die erste Region, die innerhalb Russlands ihre Grenzen schloss (mit Wirkung zum 5. April). Es ist unklar, ob andere unabhängig dem Beispiel folgen werden. Andere Regionen haben unterschiedlich strenge Kontaktverbote erlassen. Tatarstan hat das in Moskau vorgeschlagene (aber nicht flächendeckend umgesetzte) System mit obligatorischen QR-Codes oder anderen Ausweisen kopiert, die erforderlich sind, wenn Bewohner ihre Wohnung verlassen wollen. Die sibirischen Regionen Krasnojarsk, Norilsk und Tomsk haben mit Wirkung vom 6. April eine vierzehntägige Quarantäne für alle Besucher aus Moskau eingeführt. Die Bewohner von Belgorod werden jetzt mit einer Geldstrafe belegt, wenn sie privat Auto fahren. Es könnte allerdings sein, dass - wie im Fall der USA das Fehlen einheitlicher landesweiter Maßnahmen das Ausmaß und den Zeitraum, in dem die Epidemie in Russland anhält, vergrößert. Dabei könnten verschiedene Regionen über eine Reihe von Monaten hinweg Höhepunkte der Epidemie erleben, je nach dem, wann Kontaktverbote und andere Kontrollmaßnahmen eingeführt und wie strikt sie durchgesetzt werden.

Die Reaktion von Präsident Wladimir Putin auf die Coronakrise war anfangs allenfalls mau. Seine Ansprache an die Nation am 25. März, durch die die russische Regierung erstmals signalisierte, dass sie die Schwere der Bedrohung durch das Virus verstanden hat, war merkwürdig kleinlaut. Er sprach zudem fast ausschließlich über die wirtschaftlichen Folgen und überhaupt nicht über die Art der Maßnahmen, die die Gesellschaft zur Eindämmung der Epidemie ergreifen sollte. Seine ursprüngliche Verkündung eines einwöchigen bezahlten Arbeitsurlaubs war hinsichtlich einer Eindämmung der Epidemie ein riesiger Fehler: Die Menschen fassten das als eine Ankündigung von Ferien auf, und viele reisten von Moskau in andere Teile des Landes. Die Folgen dieses Missgriffs werden womöglich erst nach 7 bis 10 Tagen erkennbar werden, doch könnte dieser Schritt dafür verantwortlich werden, dass das Virus sich auch in kleineren Städten und in ländlichen Gebieten ausbreitet, in denen die medizinischen Einrichtungen schnell überfordert sein könnten.

\section{Die Kapazitäten des Gesundheitssystems als Lösung}

Im Hinblick auf die Fähigkeit des Gesundheitswesens zur Bewältigung der Epidemie gibt es zwei wichtige Fragen: 1) Wie gut sind die beiden größten Städte des Landes, Moskau und St. Petersburg ausgestattet, um eine Welle von Patienten mit mittelschweren bis ernsten Fällen von Atemnot zu bewältigen? und 2) Wird es eine beträchtliche Ausbreitung in andere Städte oder sogar in Kleinstädte und Dörfer geben, wo das Gesundheitswesen weniger entwickelt ist und schnell zusammenbrechen würde? Insgesamt verfügt das russische 
Gesundheitssystem über einige Vorteile. Sie beruhen größtenteils auf dem nachwirkenden Erbe des produktionsorientierten sowjetischen Systems, das Quantität über Qualität gestellt hatte. Das Gesundheitssystem verfügt über viele Ärzte, Krankenschwestern und anderes Personal. Angaben der OECD zufolge gibt es 4,04 Ärzte pro 1.000 Einwohner, über 50 Prozent mehr als in den Vereinigten Staaten (2,6 Ärzte) und 70 Prozent mehr als im schwer getroffenen Südkorea (2,34). Der Vorsprung bei Krankenhausbetten ist noch deutlicher: 8,05 Betten/1.000 Einwohner, fast drei Mal so viele wie in den USA $(2,77)$ oder Italien $(3,17)$. Die vertikalen Kommandostrukturen erlauben eine relativ schnelle Umleitung und Mobilisierung neuer Ressourcen. Beispiele sind das eilig gebaute neue Krankenhaus für Covid-19-Patienten am Moskauer Stadtrand und die Umwandlung anderer medizinischer Einrichtungen und Behörden im Land.

Russland verfügt über eine lange, beträchtliche Erfahrung im Umgang mit Infektionskrankheiten. Die jüngsten Erfahrungen mit Tuberkulose, einer anderen Atemwegsinfektion, die eine ausgefeilte Diagnostik und hohe Standards beim Seuchenschutz erfordern, könnten gute Dienste leisten. Russland hat es zwar nicht geschafft, die wirkstoffresistente Tuberkulose unter Kontrolle zu bringen, doch sind die Fallzahlen von TBC seit 2010 jährlich um 5-6 Prozent zurückgegangen, was eine beeindruckende Erfolgsgeschichte darstellt. Im Idealfall lassen sich die Fähigkeiten und Erfahrungen aus der Welt der Tuberkulose in einen Vorsprung bei der Bekämpfung von Covid-19 verwandeln.

Bei einem breiter gefassten Blick ist aber festzustellen, dass das russische Gesundheitssystem schlecht ausgestattet ist, um einen großen Strom von Covid-19-Patienten bewältigen zu können. Trotz erheblicher Investitionen im letzten Jahrzehnt ist der Zugang zu medizinischer Versorgung seit der Sowjetzeit zurückgegangen und qualitative Verbesserungen sind längst nicht flächendeckend. Korruption und eine verworrene Struktur der Anreize sorgen für verzerrte Entscheidungen über den Einsatz von Ressourcen. Ein großer Teil der Krankenhausausstattung ist alt und von minderer Qualität. Das medizinische Personal ist nicht gut ausgebildet. So wird beispielsweise eine Lizenz für eine medizinische Betätigung in Russland nicht automatisch in eine entsprechende Lizenz in Europa oder den USA umgewandelt. Es könnte also einen Mangel am richtigen Personal geben (Anästhesisten, Pflegepersonal für Atemwegserkrankungen, Labortechniker, Fachkräfte für Intensivstationen), die zur Behandlung von mittelschweren bis ernsten Covid-19-Fällen erforderlich sind. Die russische Regierung hat bekräftigt, dass sie mehr Beatmungsgeräte zur Verfügung hat als notwendig (insgesamt 40.000), wie auch große Vorräte an Schutzkleidung für medizinisches Personal. Einige russische Ärzte sind allerdings besorgt, dass viele dieser Beatmungsgeräte alt und nicht mehr funktionstüchtig sind, und dass weder die vorhandenen physischen Ressourcen noch das Personal, das sie zu bedienen hat, für künftige Herausforderungen ausreichen könnten. Darüber hinaus gibt es Berichte über wohlhabende Russen, die sich die knapp werdenden Beatmungsgeräte kaufen und sie für eine private Nutzung horten.

Russland verlässt sich nicht auf große Krankenhäuser mit vielen Fachabteilungen, wie das in weiten Teilen der westlichen Welt verbreitet ist. Die meisten stationären Einrichtungen sind in hohem Maße spezialisiert: Es gibt Krankenhäuser für Infektionskrankheiten, Geburtskliniken, Zentren für Herz-Kreislauf-Erkrankungen etc. Und zurecht galten die meisten der massiven Investitionen des letzten Jahrzehnts jenen Bereichen, die für die stärksten demographischen Herausforderungen des Landes am bedeutendsten sind: Geburtshilfe und Neugeborenenmedizin (zur Steigerung der Geburtenrate) und nicht übertragbare Krankheiten (Herzkrankheiten, Schlaganfälle, Krebs), um gegen die Last der vorzeitigen Sterbefälle bei Männern im erwerbsfähigen Alter vorzugehen. Eine zentrale Frage ist hier also: Ist das russische Gesundheitswesen in der Lage, in Bezug auf Personal, Infrastruktur und Ausrüstung gegen das Coronavirus aufzurüsten? Wichtig ist: Wird es in der Lage sein, die beträchtlichen Grenzen zwischen den administrativen und bürokratischen Apparaten dieser Einrichtungen und Untersektoren - zwischen denen es traditionell einen Mangel an Kommunikation und Zusammenarbeit und vielmehr den Hang zu Konkurrenz und Revierkämpfen gibt - einzureißen?

\section{Risiken und Defizite}

Diese Fragen spiegeln sich auch in den Umfragedaten wider, die das tiefe Misstrauen der russischen Gesellschaft gegenüber dem Gesundheitssystem deutlich machen. Eine Umfrage unter 6.500 Befragten in ganz Europa hat festgestellt, dass nur 13 Prozent der Russen das Vertrauen haben, dass ihr Gesundheitssystem sie mit der bestmöglichen verfügbaren Behandlung versorgen würde. Das ist ein markanter Kontrast zu den 64 Prozent in Spanien und den 63 Prozent im Vereinigten Königreich. Ähnliche Umfragen innerhalb Russlands ergaben, dass der Zugang zu medizinischer Versorgung beharrlich zu den größten Sorgen der Bevölkerung zählt (übertroffen nur von der Angst vor Inflation, Armut, Arbeitslosigkeit und Korruption). Der Zugang zu medizinischer Versorgung ist einer der wichtigsten allgemeinen Vorteile für Russland: Im Prinzip benötigt ein Bewohner mit registriertem Wohnsitz lediglich eine Karte der Pflichtversicherung, die einen umfassenden Schutz bietet. Allerdings ziehen die meisten Russen die Qualität der gebotenen Leistungen, die unter diesen Schutz fallen, in Zweifel. 
Es gibt viele Faktoren, die einen Einfluss auf das Ausmaß haben werden, in dem das Gesundheitssystem durch Covid-19 gefordert sein wird. Die Centres for Disease Control and Prevention in den USA haben vergangene Woche Daten veröffentlicht, die verdeutlichen, dass Personen mit Vorerkrankungen (Herzerkrankungen, Diabetes, chronische obstruktive Lungenerkrankungen) mit sehr viel höherer Wahrscheinlichkeit eine Intensivbehandlung benötigen, wenn sie mit dem Coronavirus infiziert sind. Russland hat es in den vergangenen 15 Jahren zwar geschafft, die Verbreitung dieser Beschwerden zu reduzieren, doch stellen sie immer noch ein Problem dar, insbesondere bei Männern im mittleren Alter. In Russland gibt es zudem eine relativ hohe Anzahl von Menschen mit anderen Krankheiten, deren Immunsystem dadurch beeinträchtigt ist (HIV, Tuberkulose, Hepatitis C), und die sich daher eher mit dem Coronavirus infizieren können.

In Russland gibt es darüber hinaus eine große Anzahl von benachteiligten, marginalisierten Menschen, deren Lage im Zusammenhang mit dem Coronavirus derzeit unklar ist. Gefängnisse sind Brutstätten für das Coronavirus (z. B. sind Hunderte Insassen und Bedienstete des berüchtigten New Yorker Gefängnis auf Riker's Island infiziert). Allerdings sind bisher noch keine Daten zu Infektionen oder Präventivmaßnahmen in Russlands Haftanstalten und Gefängnissen veröffentlicht worden. Auch die Millionen von Arbeitsmigranten in Russland leben oft unter sehr beengten unhygienischen Bedingungen in Wohnheimen oder Wohnungen, wo das Virus leicht übertragen werden kann; diese Menschen haben keine Papiere und somit keinen Zugang zu medizinischer Versorgung. Sie dürften daher wohl kaum getestet werden, falls sie erkranken.

Alles in allem geht die russische Regierung immer noch zu viele Risiken ein. So waren Hunderte zentralasiatischer Arbeitsmigranten letzte Woche auf einem Moskauer Flughafen tagelang eng zusammengepfercht, als sie auf ihren Heimflug warteten. Die Veranstaltungen zum 75. Jahrestag des Kriegsendes und zu Ehren der betagten Weltkriegsveteranen - eine der Risikogruppen - finden immer noch statt. Das Verteidigungsministerium fährt mit seinen Plänen fort, im Frühjahr 2020 landesweit die nächste Runde der Rekrutierung von Wehrpflichtigen durchzuführen. Angesichts der Größe der Gefahr wäre eindeutig ein schnelleres und robusteres Maßnahmenpaket für Kontaktsperren angeraten. Falls dies ausbleibt oder misslingt, könnte die Anfälligkeit und die Uneinheitlichkeit des russischen Gesundheitssystems für dessen tapfere Mitarbeiter bedeuten, dass sie gewaltig mit den Folgen zu kämpfen haben werden.

Übersetzung aus dem Englischen: Hartmut Schröder

\section{Über die Autorin}

Dr. Judy Twigg ist Professorin für Politikwissenschaft an der Virginia Commonwealth University in Richmond (Virginia) und Beraterin bei der Weltbank, dem Center for Strategic and International Studies in Washington, DC, und mehreren anderen Institutionen. Sie verfasst derzeit ein Buch über eine Reform des Gesundheitswesens in Eurasien.

\section{ANALYSE}

\section{Digitalisierung des Gesundheitswesens: Stand und Perspektiven von eHealth und Telemedizin in Russland}

Philipp Walther (Hochschule Fresenius)

\section{Zusammenfassung}

Russland ist angesichts seiner Größe und vieler abgelegener ruraler Gegenden prädestiniert für eine telemedizinische Versorgung. Es gibt mit dem Telemedizin-Gesetz und dem Nationalprojekt "Gesundheitswesen" eine Reihe staatlicher Initiativen, die jedoch auch zum Teil restriktive Regularien mit sich bringen. Im privaten Markt für Telemedizin gab es in letzter Zeit aufgrund geringer Nachfrage und unzureichender Finanzierung eine Bereinigung. Deutliche Veränderungen zeichnen sich jedoch derzeit durch die Corona-Pandemie ab.

\section{Einleitung}

Es sind zwei russische Wissenschaftler, die eine Theorie für die aktuell dominierenden Themen Digitalisie- rung und Gesundheit bereithalten. Aufbauend auf der zyklischen Konjunkturtheorie von Nikolai D. Kondratjew $(1892$ - 1938) entwickelte Leo A. Nefiodow (geb. 
1939) den sogenannten 6. Kondratjew-Zyklus, der diese Entwicklungen vorhersagt und erklärt. Kernthemen dieses auch gern als Megatrend bezeichnete Digitalisierung des Gesundheitswesens sind eHealth und Telemedizin. Dies bedeutet Patientenversorgung in den Bereichen Diagnostik, Therapie und Rehabilitation über räumliche Entfernungen (ortsunabhängig) unter Einsatz von Informations- und Kommunikationstechnologien. Hierzu zählen beispielsweise elektronische Patientenakten, Telekonsultationen und -konsile oder auch Medical Apps.

Über den Stand der Digitalisierung in Russland gibt es im Vergleich wenig Publikationen und Statistiken. Gleichwohl ist Russland angesichts seiner Größe prädestiniert für den Einsatz von eHealth und Telemedizin. Daher soll dieser Beitrag einen Einblick in den aktuellen Stand und die Perspektiven der Digitalisierung des Gesundheitswesens ermöglichen.

\section{Staatliche Initiativen und Gesetze}

In den letzten Jahren hat die russische Regierung die Digitalisierung in wichtigen wirtschaftlichen und sozioökonomischen Bereichen aktiv gefördert. Im Jahr 2017 hat sie die Strategie für die Entwicklung der Informationsgesellschaft in der Russischen Föderation verabschiedet, die unter anderem das digitale Gesundheitswesen umfasst. Hauptziel im Bereich der Gesundheitsfürsorge besteht darin, ein neues Modell des Gesundheitssystems zu etablieren, das parallel zum bestehenden System funktioniert und dessen Funktionen nach und nach übernehmen soll. Prognose und Planung der gesamten Gesundheitsversorgung soll auf der Basis großer Mengen populationsbezogener Gesundheitsdaten (BigData) digitalisiert werden.

Die Digitalisierung des Gesundheitswesens ist auch Teil des Nationalen Projekts "Gesundheitswesen ", das 2018 gestartet wurde. Eines der Hauptsäulen des nationalen Projekts ist die Einrichtung eines digitalen Informationskreislaufs im staatlichen Gesundheitswesen auf der Grundlage des "Einheitlichen staatlichen Gesundheitsinformationssystems" (EGISS). Bis 2024 soll der Patient über ein persönliches Konto im EGISS unter anderem in der Lage sein, einen Arzttermin zu vereinbaren, sich für eine medizinische Untersuchung zu registrieren, eine Krankenversicherung zu beantragen oder Zugang zu seinen medizinischen Dokumenten zu erhalten. Das Projekt zielt darauf ab, die Bildung einer vertikal integrierten Telemedizin - zwischen den führenden nationalen medizinischen Forschungszentren und regionalen medizinischen Organisationen - herzustellen. Bis zum Jahr 2022 sollen 925 territoriale medizinische Einheiten und 701 ländliche medizinische Stellen über telemedizinische Einrichtungen verfügen.

In einigen Regionen wurden bereits erste Pilotprojekte gestartet. Zum Beispiel testen bereits 11 Swerdlow- sker Krankenhäuser telemedizinische Technologien vor allem zur Telekonsulation. In der Region Kuban sind bereits 240 medizinische Stellen an das telemedizinische Netz angeschlossen und haben so die Möglichkeit, Telekonsile mit den Ärzten der spezialisierten regionalen medizinischen Organisationen durchzuführen.

Als einen weiteren bedeutenden Schritt ist sicherlich das Telemedizin-Gesetz $2018 \mathrm{zu}$ sehen, auch wenn der Schwerpunkt eher auf Regulierung zu liegen scheint. In dem Telemedizin-Gesetz wird der Einsatz von ITTechnologien im Gesundheitssektor geregelt und legalisierte überhaupt erst den Einsatz telemedizinischer Technologien zur Fernbehandlung. Es werden Regeln und Voraussetzungen für den Einsatz von telemedizinischen Technologien sowohl zwischen "Arzt-Patient" (Telekonsultation) als auch Telekonsile zwischen den Ärzten (»Arzt-Arzt«) festgelegt.

Im Modell »Arzt-Patient« kann die Telemedizin nur für die präventive Behandlung, die Erfassung und Analyse von Patientenbeschwerden, die Anpassung der zuvor verordneten Behandlung und auch für die Entscheidung über die Notwendigkeit einer persönlichen Untersuchung eingesetzt werden. Das Gesetz erlaubt es beispielsweise nicht, eine Ferndiagnose zu stellen.

Im "Arzt-Arzt-Modell" erlaubt das Verfahren den Ärzten, sich mit anderen spezialisierten Ärzten zu beraten und weitere Meinungen einzuholen. Die Hauptanforderung ist, dass telemedizinische Unterstützung nur durch EGISS und nur für jene Dienste bereitgestellt werden kann, für die eine bestimmte Klinik eine gültige Lizenz besitzt.

Insgesamt räumt das Gesetz den Ärzten wenig Rechte ein und reglementiert die ärztliche Behandlungsfreiheit. Der Erstkontakt muss immer persönlich erfolgen und diagnostische Leistungen sind erst gar nicht in der Liste der telemedizinischen Dienstleistungen enthalten. Auf diese Weise ist eines der prioritären Ziele der Telemedizin - die Bereitstellung qualifizierter medizinischer Versorgung für die Bewohner abgelegener Gegenden - eher fraglich.

\section{Der private Telemedizin-Markt}

Auch in Russland weckten die Möglichkeiten der Telemedizin zeitig das Interesse von Privatunternehmen. Vor allem zog es die Aufmerksamkeit vier größerer russischer Unternehmen auf sich: Megafon, MTS, Sberbank und Yandex. Doch bereits Mitte 2018 überstieg das Angebot die Nachfrage bei weitem. Einige Unternehmen, die auf die Entwicklung eines TelemedizinGeschäfts hofften, sahen sich gezwungen, den Markt zu verlassen. Im Jahr 2019 endeten die größeren Investitionen in dem Bereich, da auch die Wachstumsrate die optimistischen Prognosen nicht bestätigten. So auch die Investitionen des Telekommunikationsunternehmens 
Megafon, das 2017 Projekte im Bereich der Telemedizin gestartet hatte. Der "Gesundheitsdienst Megafon" stellte im Februar 2019 seinen Betrieb ein. Ein Vertreter des Unternehmens wies jedoch darauf hin, dass das Unternehmen an einem internationalen Neustart des Projekts arbeite.

Das Internetunternehmen Yandex erklärte 2019 ebenfalls, dass die Telemedizin in Russland kein profitables Geschäft sei und stellte weitere Investitionen in diesem Bereich zurück. Davor war das Unternehmen drei Jahre lang als Investor der medizinischen OnlinePlattform Doc+ tätig, die 20 Millionen Dollar an Investitionen aufbringen konnte. Yandex betreibt jedoch immer noch seinen eigenen telemedizinischen Beratungsdienst Yandex.Health, bei dem monatlich mehrere tausend Beratungen durchgeführt werden. Dies jedoch ohne einen Schwerpunkt auf telemedizinische Dienstleistungen.

Aufgrund der geringen privaten Marktnachfrage und den hohen gesetzlichen Anforderungen reduzierte sich die Zahl der privaten Anbieter. Es dauerte fast zwei Jahre, bis die relevanten Akteure auf dem Markt der telemedizinischen Konsultationen eine der Anforderungen der Regulierungsbehörde erfüllt und sich in die EGISS integriert hatten. Eine der ersten, die sich an das System anschlossen, war der telemedizinische Service DocDoc, dessen Hauptaktionär die Sberbank ist. Um sich an die EGISS anzuschließen, musste DocDoc eine medizinische Lizenz erhalten.

Die DocDoc-Plattform wird für die Bereitstellung von telemedizinischen Dienstleistungen im Rahmen einer privaten medizinischen Krankenversicherung (DMS) angeboten. Laut den im Februar 2020 veröffentlichten Statistiken deckte dieses Versicherungsprogramm 5 Millionen Menschen ab. Die Nachfrage nach Telemedizin unter den Versicherten verdreifachte sich 2019 im Vergleich zum Vorjahr. Die Telemedizin wurde am aktivsten von Kunden im Alter von 25 - 40 Jahren genutzt (61\%). An zweiter Stelle stehen 40 - 55 Jahre alte Patienten (27\%), an dritter Stelle Menschen über 55 Jahre $(10 \%)$. Am häufigsten benötigten die Klienten eine Beratung durch Hausärzte $(70 \%)$ und Kinderärzte $(12 \%)$.

Darüber hinaus gibt es eine Reihe weiterer privater telemedizinischer Angebote wie beispielsweise "Kinderarzt 24/7«, "Online-Arzt« oder »Ondoc«. Erwähnenswert sind weiterhin die privat-öffentlichen Initiativen. Das Nationale Zentrum für Informatisierung (NCI) und das Russische Zentrum für Katastrophenmedizin starten mit "Saschita" (Schutz) ein gemeinsames Projekt, das auf den Aufbau der russischen telemedizinischen Infrastruktur abzielt und Fernkonsultationen mit 21 föderalen hochspezialisierte medizinischen Forschungszentren ermöglichen soll. Ach die Russische Post startet zusammen mit dem Unternehmen Mobile Medical Technologies ein Pilotprojekt zur Installation von telemedizinischen Komplexen in abgelegenen Regionen.

Die nationale Qualitätsüberwachungsbehörde Roskachestvo kündigte an, dass man telemedizinische Anwendungen auf ihre Sicherheit hin überprüfen und eine Bewertung der Dienste vornehmen werde. Die Ergebnisse sollen im Herbst 2020 vorgestellt werden. Zunächst ist geplant, die Informationssicherheit bei der Nutzung von telemedizinischen Anwendungen zu bewerten, einschließlich der Sicherheit der übermittelten personenbezogenen Daten, ebenso wie die Anwenderfreundlichkeit, die Anpassungsfähigkeit für Menschen mit Behinderungen und die Funktionalität.

\section{Perspektiven vor und nach der Corona-Pandemie}

Bis Anfang 2020 wurde der Markt für Telemedizin von Experten verhalten optimistisch eingeschätzt. Wachstumsraten für telemedizinischen Dienstleistungen waren mit $3 \%$ noch gering, jedoch sah man mittelfristig deutliches Wachstumspotential. Nach der Prognose von Jekaterina Kolomenseva, Direktorin für die Entwicklung der Krankenversicherung der IC Sberbank Life Insurance, sollten in den nächsten 3 - 5 Jahren etwa $20 \%$ der russischen Bevölkerung durch Telemedizin versorgt werden. Experten prognostizierten bislang, dass das Marktvolumen für eHealth und Telemedizin bis in das Jahr 2023 in der Russischen Föderation 90 Milliarden Rubel erreichen könnte.

Durch die Corona-Pandemie wird man diese Einschätzung vermutlich revidieren müsssen. Wie in vielen anderen Ländern auch, beschleunigt es die digitale Transformation im Gesundheitswesen, da es beispielsweise zu telemedizinischen Fernbehandlungen in vielen Fällen keine Alternativen gibt. Am 25. März 2020 wurde in der russischen Staatsduma ein Gesetz vorgelegt, das es der Regierung während einer Epidemie und in Notfallsituationen im Falle eines Mangels an medizinischem Personal ermöglicht, Änderungen in der medizinischen Versorgung vorzunehmen - einschließlich der Nutzung von Telemedizin. Es wird erwartet, dass der Gesetzentwurf den Ärzten erlaubt, unter anderem auch die (Erst-)Diagnostik per Telekonsultation durchzuführen. Der Gesetzentwurf wurde vom Rat für die Entwicklung der digitalen Wirtschaft unter dem Föderationsrat entwickelt und wird seit Februar 2020 in den zuständigen Ministerien diskutiert. Die aktuelle Situation der Coronavirus-Pandemie beschleunigte seine Vorlage zur Beratung im Parlament.

Experten haben keinen Zweifel daran, dass das Coronavirus zur Entwicklung der Telemedizin beitragen wird. Georgij Lebedew, Direktor des Instituts für digitale Medizin an der Universität Sechenow, sagt, dass dies 
bereits in Echtzeit geschieht. Die Medizinische Universität Sechenow eröffnete ein Zentrum für den Kampf gegen das Coronavirus und richtete zwei neue vollständig eingerichtete Intensivstationen zur Behandlung von Patienten mit COVID-19 ein. Außerdem wurde ein Beratungszentrum eingerichtet, in dem jeder Arzt eine Arzt-Arzt-Sprechstunde beantragen und sich von medizinischen Spezialisten beraten lassen kann.

Sberbank hat zudem die Regierung aufgefordert, den Bürgern freien Zugang zu medizinischer Beratung im Zusammenhang mit dem Coronavirus zu gewähren. Die Telekonsultationen werden über dessen telemedizinischen Dienst DocDoc durchgeführt, der Teil des Sberbank-Ecosystems ist. Die Initiative wurde bereits am 23. März 2020 gestartet und zielt in erster Linie darauf $a b$, älteren Menschen und Menschen in Quarantäne zu helfen.

Auch die private Moskauer Poliklinik-Kette Doktor von nebenan hat zusammen mit der staatlichen Entwicklungsgesellschaft VEB.RF ein Projekt zur kostenlosen telemedizinischen Betreuung von Patienten gestartet. Dem Projekt schlossen sich weitere private Anbieter wie Niarmedic und Scandinavian Health Center an. Finanziell gefördert wird die Initiative durch die staatliche VEB.RF.

\section{Diskussion}

Die Gründe einer bislang eher zurückhaltenden Umsetzung einer breiten Digitalisierung des Gesundheitswe- sens sind durchaus mit denen in Deutschland zu vergleichen. Neben einer ausreichenden Finanzierung der Digitalisierungsprojekte ist eine weitere Voraussetzung die notwendige Infrastruktur vor allem in abgelegenen Regionen, die erst den Einsatz telemedizinischer Technologien ermöglicht. Zudem ist eine staatliche Regulierung und Reglementierung der Telemedizin zu sehen, die vor dem Hintergrund der Corona-Pandemie jedoch neu ausgerichtet wird. Treiber der Digitalisierung sind in vielen Ländern private Unternehmen, die von der derzeitigen Situation, vermutlich auch in Russland, profitieren werden. Mittel- und langfristig sind die Voraussetzungen für eine breite Digitalisierung des Gesundheitswesens jedoch eine ausreichende Finanzierung und die Schaffung der entsprechenden technischen Infrastruktur.

Einer der Erklärungsansätze für die eingangs erwähnten Kondratjew-Zyklen der russischen Wissenschaftler ist ein akuter Bedarf in bestimmten Bereichen, der entsprechende Innovationen auslöst. Folgt man dieser Logik, so könnte man die derzeitige Situation dahingehend interpretieren, dass wir vermutlich derzeit am Anfang des 6. Kondratjew-Zyklus und damit auch der Digitalisierung des Gesundheitswesens in Russland stehen.

\section{Über den Autor}

Prof. Dr. Philipp Walther ist Professor und Studiendekan für Gesundheitsmanagement an der Hochschule Fresenius. Im digitalen Fachbereich onlineplus beschäftigt er sich schwerpunktmäßig mit der digitalen Transformation des Gesundheitswesens.

\section{Russland und Corona}

Jens Siegert (Moskau)

G emessen an den meisten anderen europäischen I Staaten war Russland ein Corona-Frühstarter. Schon Ende Januar wurde die Grenze zu China geschlossen, kurze Zeit später die Einreise aus China begrenzt und chinesische Staatsbürger in Moskau unter besondere Beobachtung gestellt. Die ersten beiden dokumentierten Infizierten (in Sibirien) waren ebenfalls Chinesen und wurden recht schnell in Quarantäne gebracht
Das Virus wurde in der russischen Presse vorwiegend "chinesisches Virus" genannt.

Bis heute lobt sich die Staatsführung für diese schnelle und, wie sie sagt "entschiedene« Reaktion. Eben deshalb habe Russland eine gute Chance, zu vermeiden, dass die Epidemie so schwere Formen annimmt wie in vielen EU-Staaten. Tests, vor allem an Einreisenden, seien schnell flächendeckend ausgeführt worden. Offi- 
ziell kommt schon seit Mitte März niemand mehr ohne Test ins Land. Damit und mit einer Reihe anderer Maßnahmen erklärt die Staatsführung, weshalb es in Russland bisher, verglichen mit anderen Ländern, deutlich weniger offiziell registrierte Corona-Infizierte und fast keine Corona-Toten gibt (Stand 28.3.: 1264 Infizierte und 4 Tote, 29.3.: 1534 Infizierte und 8 Tote).

Zweifel an dieser Version gibt es aus unterschiedlichen Gründen:

- Die Tests wurden lange Zeit nur sehr selektiv durchgeführt, vor allem an aus dem Ausland Einreisenden und ihren Kontaktpersonen. Menschen mit Symptomen, aber ohne Kontakt zu diesen Risikopersonen wurden bis vor Kurzem kaum getestet.

- Diese Testpolitik wurde bis Ende März auch davon gestützt, wie die Verantwortlichen im Staat über die Pandemie sprachen. Sie stellten sie als eine vor allem äußere Bedrohung dar, gegen die man das Land abschotte und so schütze. Über andere Risiken der Weitergabe des Virus im Land wurde kaum gesprochen. Entsprechend wenig ernst nahmen viele Menschen im Land die Gefahr. Noch Mitte März waren doppelt so viele Menschen davon überzeugt, dass die scharfe Abwertung des Rubels (in Folge des Ölpreisverfalls) ein viel größeres Problem darstelle als das Virus.

- Der anfangs einzige zugelassene Test stammt aus einem Labor in Nowosibirsk. Er wird in vielen Veröffentlichungen als vergleichsweise ungenau beschrieben, so dass die Gefahr sehr groß ist, dass viele negativ Getestete tatsächlich das Virus in ihren Körpern tragen. Auch hinkte die offizielle Statistik infizierter Personen lange Zeit hinterher, weil in Moskau, dem Ansteckungszentrum, durchgeführte Tests erst nach einer Bestätigung durch dieses Labor in die Statistik aufgenommen wurden. Dazu mussten die Testproben mit dem Flugzeug nach Sibirien gebracht werden. Die hohe Auslastung des Labors verzögerte die Testergebnisse zusätzlich. Das änderte sich erst am 23. März, als weitere Labors zugelassen wurden und positive Tests sofort nach dem ersten Testergebnis vor Ort in die Statistik aufgenommen wurden. In der internationalen Diskussion ist man sich inzwischen einig, dass es einen direkten Zusammenhang zwischen Testhäufigkeit, Testgenauigkeit, Testkriterien und den in den Statistiken veröffentlichten Fallzahlen gibt.

Eine mit Alexej Nawalnyjs »Stiftung zur Bekämpfung der Korruption« verbundene Russische Ärzte-Union hat Mitte März einen Bericht vorgelegt, in dem über einen verdächtigen Anstieg von Lungenentzündungen von bis zu 30\% in Moskau im ersten Quartal 2020 gegenüber dem Vorjahresquartal die Rede ist (https:// www.businessinsider.com/coronavirus-russia-doctors- say-government-is-covering-up-cases-2020-3? utmSour ce=twitter\&utmContent $=$ referral\&utmTerm $=$ topbar\& referrer=twitter). Sie vermutet, dass sich dahinter eine größere Anzahl von Corona-Toten verbirgt.

Es gibt in Russland ein grundsätzliches Misstrauen gegenüber dem Staat im Allgemeinen und dem Gesundheitssystem im Besonderen. Ich kenne viele Menschen (eigentlich die meisten), die sagen, selbst wenn sie Symptome hätten, aber nicht ernsthaft erkrankt wären, würden sie nicht den Arzt rufen, weil sie dem russischen Staat (auch in Form seines Gesundheitssystems) nicht trauen. Weder seiner Kompetenz, noch dass es ihm darum geht, wirklich den Leuten zu helfen und nicht sich selbst.

Die russische Statistik ist schon in Nicht-Krisenzeiten unzuverlässig. Das hat verschiedene Gründe. Man kann es wohl durchaus eine Art Gewohnheit der Führungsspitze nennen, schlechte Nachrichten zurück zu halten, während umgekehrt kaum ein Untergebener schlechte Nachrichten nach oben melden möchte. Niemand weiß, in welchem Umfang unten Daten manipuliert wurden (oder auch nur kreativ interpretiert und zusammengestellt), um Zahlen zu erzeugen, die denen oben genehm sind. Von Kriminalitätsraten bis zu Wirtschaftsdaten ist dieses Verhalten gut belegt und mir fällt kein Grund ein, warum das bei Corona anders sein sollte. Eher im Gegenteil.

Nachdem sich, wie überall erst langsam und dann mit steigernder Geschwindigkeit, die Erkenntnis über die Schwere der Krise durchzusetzen begann, stand die russische Regierung vor der gleichen Frage, wie alle anderen Staaten: Wie können die Menschen und insbesondere die Älteren und die Schwächeren am besten geschützt werden, ohne die Wirtschaft allzu sehr zu belasten. Allerdings kommt im Fall Russlands eine Besonderheit hinzu. Die Stabilität des politischen Systems (und ich betone, des Systems, nicht der Regierung) hängt viel stärker als in demokratischen Staaten an der Popularität Wladimir Putins. Jedes Agieren wird im Kreml deshalb wohl noch mehr als anderswo daraufhin abgeprüft, wie es auf Putins Popularität zurückwirkt. Anders ausgedrückt: Es gibt die starke Neigung, Entscheidungen noch mehr eher aufgrund von politischen Notwendigkeiten, denn aufgrund sachlicher Abwägungen zu treffen als anderswo.

Verschärfend kommt hinzu, dass genau in dem Moment, in dem aus der chinesischen Corona-Epidemie eine Pandemie wurde, Putin erklärte, vielleicht doch nach 2024 Präsident bleiben zu wollen. Viele Beobachter/innen, auch ich, halten dieses Zusammenfallen nicht für einen Zufall. Vielmehr sieht es sehr danach aus, als wollte der Kreml durch die (gerechtfertigterweise) überragende Aufmerksamkeit für die Pandemie den schleichenden Staatsstreich von oben kaschieren 
oder zumindest den zu erwartenden Widerstand erheblich verringern. Das hat auch ausgezeichnet geklappt. In einer Blitzaktion wurden die Verfassungsänderungen innerhalb von knapp einer Woche durch die Instanzen Staatsduma, Föderationsrat, Regionalparlamente und Verfassungsgericht gebracht und sollten am 22. April ihre höheren Legitimitätsweihen in einer Volksabstimmung erlangen. Die kleine Opposition drang mit ihren Argumenten kaum durch und im Westen ist man mit Corona beschäftigt. Doch dann überschlugen sich die Ereignisse.

Etwa um den 20. März wurde allmählich klar, dass auch Russland das Virus nicht würde einfach aussitzen können. Während Kremlsprecher und Regierung noch erklärten, sie hätten alles im Griff, erließ der von Putin zum landesweiten Anti-Corona-Koordinator gemachte Moskauer Bürgermeiste Sergej Sobjanin fast im Tagesrhythmus neue und immer schärfere Beschränkungen für die Einwohner der 15-Millionen-Stadt. Am 23. März wurden die Tests auf weitere Verdachtsgruppen ausgeweitet und neben dem Nowosibirsker Labor weitere Labors in Moskau zum Testen zugelassen.

Am 24. März tauchte auf der Kremlwebsite ein Video auf, dass Putin in einer seiner Residenzen im Moskauer Umland zusammen mit dem Moskauer Bürgermeister Sobjanin zeigte. Das Besondere dieses etwa sechs Minuten langen Gesprächs war, dass vor allem Sobjanin sprach, während Putin lediglich zuhörte und nur mitunter zustimmende Kommentare abgab. Sobjanin sagte, es gebe "weit mehr" Ansteckungsfälle, als die offizielle Statistik ausweise. Das Land solle sich nicht in Sicherheit wiegen. Und Putin wiegte seinen Kopf. Diese seltsame Rollenumkehr verdient etwas mehr Aufmerksamkeit. Zwei Erklärungen sind möglich. Angesichts der (ganz entgegen seines vorherrschenden Images) notorischen Risikoaversion Putins, ist es durchaus denkbar, dass Sobjanin in die erste Reihe geschoben wurde, weil die Situation so unübersichtlich ist, wie sie nun einmal überall auf der Welt ist. Putin, so die mögliche Überlegung dahinter, habe erst einmal solange nichts zu gewinnen, solange nicht klar ist, wie das Virus besiegt werden kann. Sollte Sobjanin mit seinen immer schärferen Maßnahmen scheitern, bliebe das an ihm hängen und nicht an Putin. Sollten sich diese Maßnahmen als richtig herausstellen, könnte sich Putin immer noch an die Spitze der Bewegung stellen und den Sieg für sich reklamieren. Immerhin hatte er ja Sobjanin zum Krisenbeauftragten ernannt.

Sollte es solche Überlegungen gegeben haben, hielten sie nicht lange. Denn schon kurze Zeit später noch am selben Tag zeigte das Fernsehen Putin bei einem Besuch des Corona-Haupt-Krankenhauses am Rande Moskaus. Diese Szene hatte etwas Gespenstiges. Putin marschierte in einem kanariengelben Schutzanzug mit exakt so einer Atemmaske, wie sie die Helden der USamerikanischen Fernsehserie Breaking-Bad beim Christal-Meth-Kochen benutzten, vor einer Gruppe Männer in weißer Schutzkleidung durch die Krankenhauskorridore. Der Chefarzt des Krankenhauses, Denis Prozenko, erklärte seinem Präsidenten, er halte einen schweren Verlauf der Pandemie, ein »italienisches Szenarium«, durchaus für möglich. Nur mit Glück könne man daran vorbeischrammen und bei einem "asiatischen Szenarium» landen. Erneut nickte Putin fast ergeben. Ein Interview seines Sprechers Dmitrij Peskow erklärt diese für Putin unerhörte Ergebenheit vielleicht ein bisschen (wobei die Aufrichtigkeit Peskows immer aller Zweifel würdig ist). Dieser Krankenhausbesuch, so Peskow, habe "unerwartet und unvorbereitet« stattgefunden. Die nun neue Message an die Öffentlichkeit war aber klar, und sie war interessanterweise die gleiche wie die von Angela Merkel in ihrer Fernsehansprache an die Deutschen: Corona ist ernst und der Kreml möchte, dass alle in Russland das Virus auch ernst nehmen.

Ein kleiner Einschub: Am 30. März berichteten russischen Medien, Chefarzt Prozenko sei positiv auf das Virus getestet worden. In sozialen Netzwerken tauchten ein Foto auf, dass zeigte, wie Putin Prozenko zur BegrüBung die Hand reichte, beide noch ohne Handschuhe, Schutzanzüge und Masken. Putinsprecher Dmitrij Peskow versicherte eiligst, Putin werde regelmäßig auf das Virus getestet. Das sei auch nach dem Krankenhausbesuch bereits geschehen, mit negativem Resultat.

Am Tag nach dem Krankenhausbesuch, am 25. März, wandte sich Putin in einer 17-minütigen Fernsehansprache an die Bevölkerung (https://www.rbc.ru/politics/ 25/03/2020/5e7b32999a7947d5d4f9e169). Er begann mit dem impliziten (wenn auch nicht expliziten) Eingeständnis, dass die bisherige Strategie, der Pandemie Herr zu werden, gescheitert war: Ein »Schutz vor der Epidemie« sei "aufgrund der geographischen Lage« Russlands "objektiv nicht möglich". Dann verkündete er zwei politische und zahllose wirtschaftliche Maßnahmen. Die Abstimmung über die Verfassungsänderungen wurde auf unbestimmte Zeit verschoben und die nächste Woche (vom 30. März bis zum 3. April) bei vollem Lohnausgleich für arbeitsfrei erklärt. Die verkündeten wirtschaftlichen Maßnahmen unterscheiden sich nicht wesentlich von ähnlichen Programmen anderer Staaten, wenn sie auch weit hinter dem Umfang in der EU oder in den USA zurückbleiben. Sie alle sollen dazu dienen, Bürger/innen und Unternehmen das (wirtschaftliche) Überleben in der Krise zu ermöglichen: Staatsgarantien für Unternehmen, Steueraufschübe, Stundungen von Verbraucherkrediten und Ähnliches mehr.

Doch diese scharfe und unerwartete Wende drang nicht wirklich, zumindest nicht schnell (genug) zu einem großen Teil der Bevölkerung durch. Dazu hat 
sicher auch beigetragen, dass weder Putin noch andere höhergestellte Politiker/innen, noch die Staatsmedien sich viel Mühe machten, zu erklären, warum alle diese Maßnahmen nun plötzlich notwendig sind, nachdem sie kurz zuvor doch noch »alles im Griff" zu haben schienen. Dafür war mehr von Verboten und verschärften Strafen bei ihrer Nichtbeachtung die Rede. Schnell begann die Duma Gesetze entsprechend zu ändern. Das Unwissen über das Ausmaß und die Art der Pandemie blieb auch deshalb weiter ebenso groß wie die Sorglosigkeit in der Bevölkerung. Die Bereitschaft, sich einzuschränken, dagegen blieb klein; der Alltag änderte sich nicht. Folgerichtig verhängte Bürgermeister Sobjanin nur fünf Tage nach der Putin-Ansprache ein faktisches Ausgehverbot für Moskau ab dem 30. März. Der Kreml empfahl daraufhin allen anderen russischen Regionen, zu ähnlichen Maßnahmen zu greifen.

In Deutschland und der EU wird unter anderem viel darüber diskutiert, welche Gefahren von den massiven Einschränkungen vieler Freiheitsrechte im Namen der Pandemiebekämpfung ausgehen und ob der Staat sich nicht unter diesem Deckmantel zu viele Kontrollrechte dauerhaft zu sichern versuchen könnte. Diese Diskussion gibt es in Russland nur sehr marginal in oppositionellen Kreisen. Das mag auch damit zu tun haben, dass der russische Staat unter Putin, der sonst mit Bürgerrechten nicht sonderlich zimperlich umzugehen pflegt, sich ausgerechnet zu Pandemiezeiten bisher überraschend zögerlich zeigt. Diese Zögerlichkeit (Zurückhaltung würde ich es nicht nennen) verwundert besonders, weil es ja eigentlich ein günstiger Zeitpunkt wäre, die sonst so gescheute internationale Kritik zu vermeiden, weil gegenwärtig (fast) alle denkbaren Einschränkungen auch im Westen als gerechtfertigt angesehen werden und ein Rückblick zeigt, dass der russische Staat und insbesondere Putin auf eine lange Geschichte zurückblicken können, solche Gelegenheiten zu nutzen.

Zum Teil mag die Antwort darin liegen, dass die wirtschaftliche Krise aufgrund der Pandemie eher ein Geschenk für den Kreml ist, weil sich die langjährige wirtschaftliche Stagnation nun recht leicht mit ihr und der daraus entstandenen Erdölbaisse erklären lässt. Erneut kommt alles Böse von außen. Es ist allerdings auch nicht ganz auszuschließen, dass diese Version der Dinge im Kreml selbst zu viel geglaubt wurde und, zumindest teilweise, die verspätete (vielleicht gar zu späte) Reaktion auf die Pandemie erklärt. Die seltsam zögerliche Reaktion des Kremls weist aber auch noch einmal darauf hin, dass die repressive Macht des politischen Regimes von vielen (auch und gerade im Westen) oft erheblich überschätzt wird. Putin stützt seine Macht auf eine Mischung aus Legitimität, wirtschaftlichem Erfolg und der selektiven Verfolgung Andersdenkender und der Opposition, die oft mehr Abschreckung ist als flächendeckende Repression. Die politische Stabilität wird dabei eher, wie Lew Gudkow, der Direktor des Lewada-Zentrums, nicht müde wird zu betonen, von einer "passiven Duldung" einer Bevölkerungsmehrheit gestützt, denn von aktiver Teilhabe. Diese Überschätzung der repressiven Fähigkeiten des Kremls sind eine seiner wichtigsten Machtressourcen.

Der abrupte U-Turn am 25. März zeigt, wie stark sich Putin in Bezug auf die von der Pandemie ausgehenden gesundheitlichen, wirtschaftlichen und damit auch politischen Gefahren verschätzt hat. Er zeigt aber, gerade wegen seiner Schärfe und Abruptheit, auch, dass das Regime nicht verlernt hat, aus Fehlern zu lernen und umzusteuern.

Ein kleines P.S.: Bei aller, wie ich finde begründeten Kritik am staatlichen Handeln in Russland im Angesicht der Corona-Pandemie, habe ich, ganz tief im Inneren, die Hoffnung noch nicht aufgegeben, dass es hierzulande wirklich nicht so schlimm kommen wird, wie in Italien, Frankreich oder Spanien oder vielleicht nicht einmal so schlimm wie in Deutschland. Die Hoffnung also, dass einmal, nur einmal Wiktor Tschernomyrdin mit seinem berühmten Aphorismus nicht recht behält: "Wir wollten es besser machen, aber es ist wie immer gekommen."Hoffnung stirbt halt, ein Sprichwort wohl überall auf der Welt, immer zuletzt. Ein deutscher Dichter hatte darauf allerdings schon im 19. Jahrhundert seine eigene Sicht: "Doch in allem, was wir hoffen, hat uns schon Verdruss getroffen«.

\section{Über den Autor}

Jens Siegert lebt seit 1993 in Moskau. Er war Korrespondent, hat mehr als 15 Jahre das Moskauer Büro der HeinrichBöll-Stiftung geleitet und bemüht sich seit einigen Jahren, im Auftrag der EU Public Diplomacy in und mit Russland zu fördern.

Dieser Beitrag von Jens Siegert erschien in seinem Blog (russland.boellblog.org/) am 02.04.2020. 


\section{Covid-19 in Russland}

Grafik 1: $\quad$ Ausbreitung von Covid-19 im Vergleich (1. März - 15. April 2020)

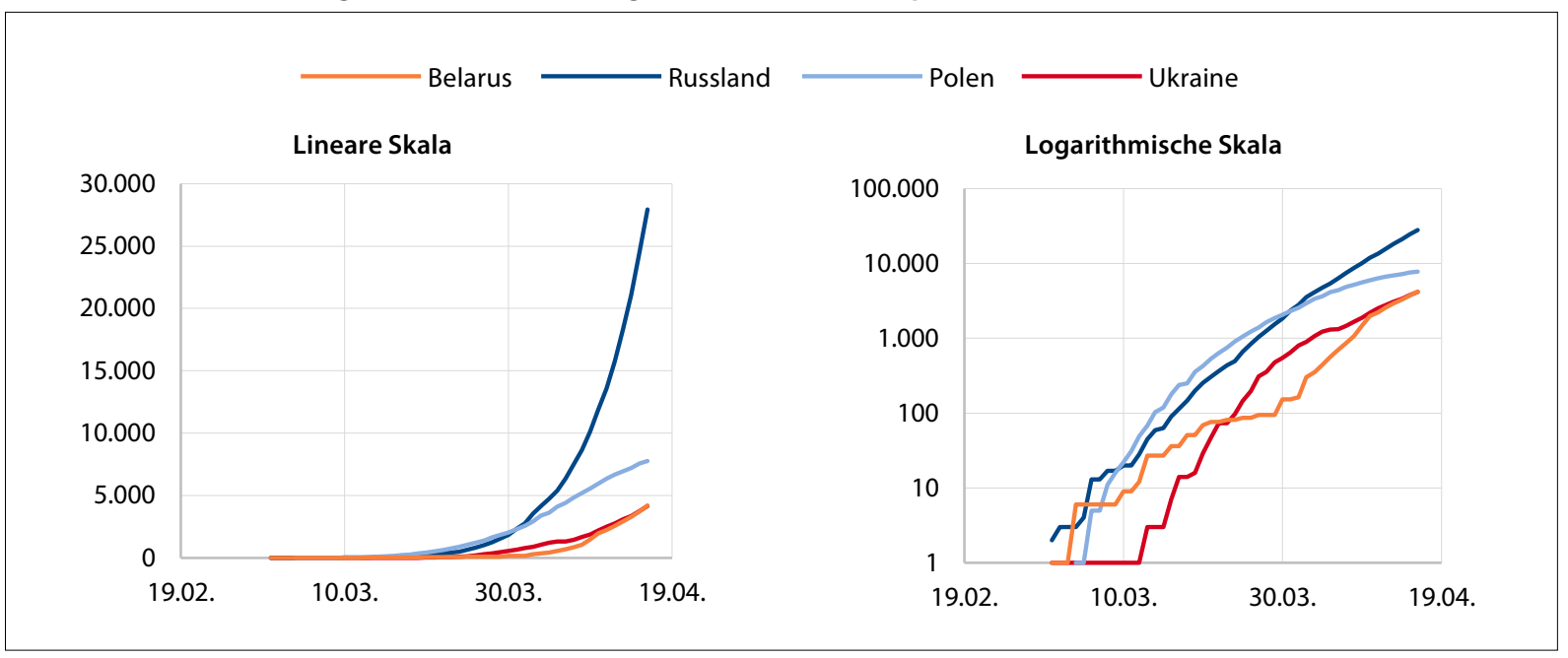

\begin{tabular}{|c|r|r|r|r|}
\hline Datum & Belarus & Polen & Russland & Ukraine \\
\hline 01.03. & 1 & & 2 & 1 \\
\hline 02.03. & 1 & & 3 & 1 \\
\hline 03.03. & 1 & & 3 & 1 \\
\hline 04.03. & 6 & 1 & 3 & 1 \\
\hline 05.03. & 6 & 1 & 4 & 1 \\
\hline 06.03. & 6 & 5 & 13 & 1 \\
\hline 07.03. & 6 & 5 & 13 & 1 \\
\hline 08.03. & 6 & 11 & 17 & 1 \\
\hline 09.03. & 6 & 16 & 17 & 1 \\
\hline 10.03. & 9 & 22 & 20 & 1 \\
\hline 11.03. & 9 & 31 & 20 & 1 \\
\hline 12.03. & 12 & 49 & 28 & 1 \\
\hline 13.03. & 27 & 68 & 45 & 3 \\
\hline 14.03. & 27 & 103 & 59 & 3 \\
\hline 15.03. & 27 & 119 & 63 & 3 \\
\hline 16.03. & 36 & 177 & 90 & 7 \\
\hline 17.03. & 36 & 238 & 114 & 14 \\
\hline 18.03. & 51 & 251 & 147 & 14 \\
\hline 19.03. & 51 & 355 & 199 & 16 \\
\hline 20.03. & 69 & 425 & 253 & 29 \\
\hline 21.03. & 76 & 536 & 306 & 47 \\
\hline 22.03. & 76 & 634 & 367 & 73 \\
\hline 23.03. & 81 & 749 & 438 & 73 \\
\hline 24.03. & 81 & 901 & 495 & 97 \\
\hline 25.03. & 86 & 1.051 & 658 & 145 \\
\hline
\end{tabular}

\begin{tabular}{|r|r|r|r|r|}
\hline Datum & Belarus & Polen & Russland & Ukraine \\
\hline 26.03. & 86 & 1.221 & 840 & 196 \\
\hline 27.03. & 94 & 1.389 & 1.036 & 310 \\
\hline 28.03. & 94 & 1.638 & 1.264 & 356 \\
\hline 29.03. & 94 & 1.862 & 1.534 & 475 \\
\hline 30.03. & 152 & 2.055 & 1.836 & 548 \\
\hline 31.03. & 152 & 2.311 & 2.337 & 645 \\
\hline 01.04. & 163 & 2.554 & 2.777 & 794 \\
\hline 02.04. & 304 & 2.946 & 3.548 & 897 \\
\hline 03.04. & 351 & 3.383 & 4.149 & 1.072 \\
\hline 04.04. & 440 & 3.627 & 4.731 & 1.225 \\
\hline 05.04. & 562 & 4.102 & 5.389 & 1.308 \\
\hline 06.04. & 700 & 4.413 & 6.343 & 1.319 \\
\hline 07.04. & 861 & 4.848 & 7.497 & 1.462 \\
\hline 08.04. & 1.066 & 5.205 & 8.672 & 1.668 \\
\hline 09.04. & 1.486 & 5.575 & 10.131 & 1.892 \\
\hline 10.04. & 1.981 & 5.955 & 11.917 & 2.203 \\
\hline 11.04. & 2.226 & 6.356 & 13.584 & 2.511 \\
\hline 12.04. & 2.578 & 6.674 & 15.770 & 2.777 \\
\hline 13.04. & 2.919 & 6.934 & 18.328 & 3.102 \\
\hline 14.04. & 3.281 & 7.202 & 21.102 & 3.372 \\
\hline 15.04. & 3.728 & 7.582 & 24.490 & 3.764 \\
\hline 16.04. & 4.204 & 7.771 & 27.938 & 4.161 \\
\hline
\end{tabular}

Quelle: Johns Hopkins Universität. Stand: 16.04.2020. 17:46 Uhr https://coronavirus.jhu.edu/map.html; https://github.com/CSSEGISandData/COVID-19/blob/ master/csse_covid_19_data/csse_covid_19_time_series/time_series_covid19_confirmed_global.csv 
Grafik 2: $\quad$ Todesfälle durch Covid-19 im Vergleich (1. März - 15. April 2020)

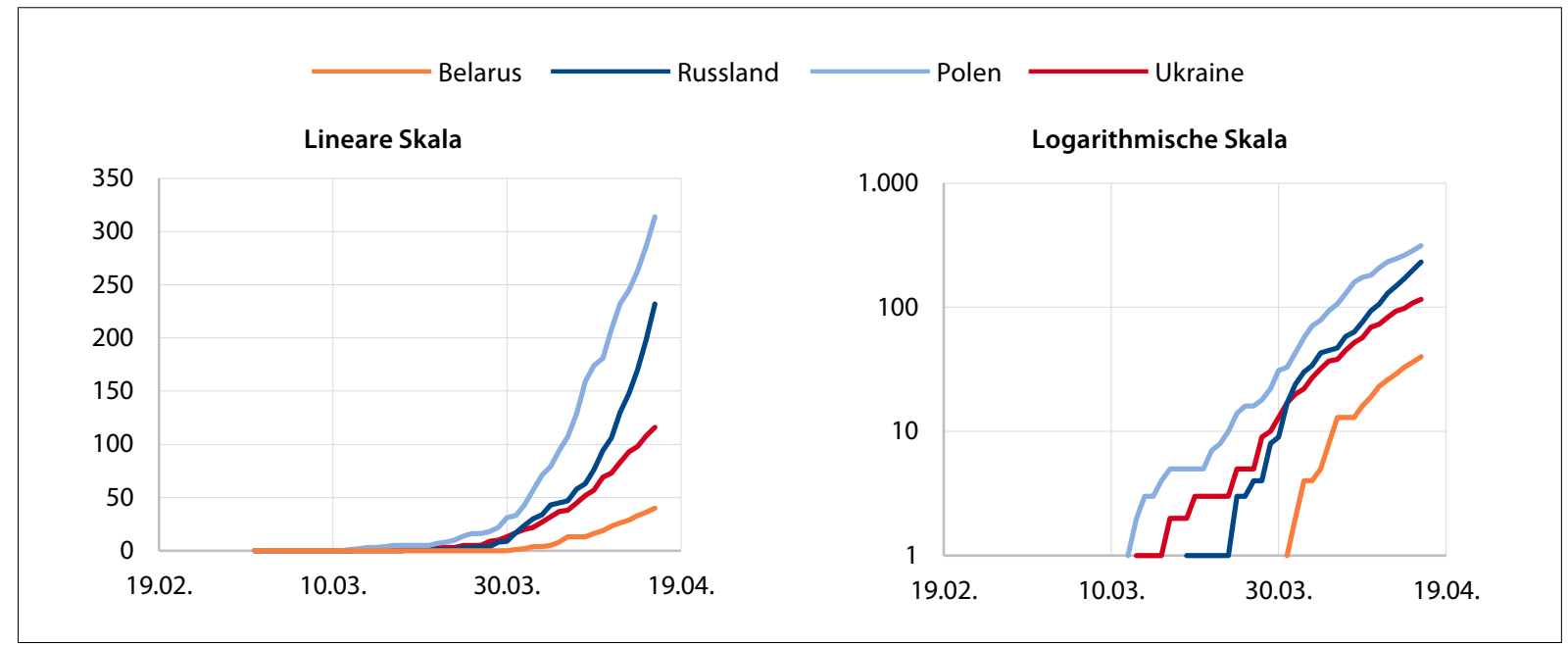

\begin{tabular}{|c|c|c|c|c|c|c|c|c|c|}
\hline Datum & Belarus & Polen & Russland & Ukraine & Datum & Belarus & Polen & Russland & Ukraine \\
\hline 01.03. & 0 & 0 & 0 & 0 & 26.03 & 0 & 16 & 3 & 5 \\
\hline 02.03 & 0 & 0 & 0 & 0 & 27.03 & 0 & 16 & 4 & 5 \\
\hline 03.03 & 0 & 0 & 0 & 0 & 28.03. & 0 & 18 & 4 & 9 \\
\hline 04.03. & 0 & 0 & 0 & 0 & 29.03. & 0 & 22 & 8 & 10 \\
\hline 05.03 & 0 & 0 & 0 & 0 & 30.03. & 0 & 31 & 9 & 13 \\
\hline 06.03 & 0 & 0 & 0 & 0 & 31.03. & 1 & 33 & 17 & 17 \\
\hline 07.03 & 0 & 0 & 0 & 0 & 01.04. & 2 & 43 & 24 & 20 \\
\hline 08.03. & 0 & 0 & 0 & 0 & 02.04 & 4 & 57 & 30 & 22 \\
\hline 09.03. & 0 & 0 & 0 & 0 & 03.04 & 4 & 71 & 34 & 27 \\
\hline 10.03 & 0 & 0 & 0 & 0 & 04.04 & 5 & 79 & 43 & 32 \\
\hline 11.03. & 0 & 0 & 0 & 0 & 05.04 & 8 & 94 & 45 & 37 \\
\hline 12.03 & 0 & 1 & 0 & 0 & 06.04 & 13 & 107 & 47 & 38 \\
\hline 13.03. & 0 & 2 & 0 & 1 & 07.04 & 13 & 129 & 58 & 45 \\
\hline 14.03. & 0 & 3 & 0 & 1 & 08.04. & 13 & 159 & 63 & 52 \\
\hline 15.03. & 0 & 3 & 0 & 1 & 09.04. & 16 & 174 & 76 & 57 \\
\hline 16.03 & 0 & 4 & 0 & 1 & 10.04 & 19 & 181 & 94 & 69 \\
\hline 17.03 & 0 & 5 & 0 & 2 & 11.04 & 23 & 208 & 106 & 73 \\
\hline 18.03 & 0 & 5 & 0 & 2 & 12.04 & 26 & 232 & 130 & 83 \\
\hline 19.03 & 0 & 5 & 1 & 2 & 13.04 & 29 & 245 & 148 & 93 \\
\hline 20.03 & 0 & 5 & 1 & 3 & 14.04 & 33 & 263 & 170 & 98 \\
\hline 21.03 & 0 & 5 & 1 & 3 & 15.04. & 36 & 286 & 198 & 108 \\
\hline 22.03 & 0 & 7 & 1 & 3 & 16.04 & 40 & 314 & 232 & 116 \\
\hline 23.03. & 0 & 8 & 1 & 3 & & & & & \\
\hline 24.03 & 0 & 10 & 1 & 3 & & & & & \\
\hline 25.03 & 0 & 14 & 3 & 5 & & & & & \\
\hline
\end{tabular}

Quelle: Johns Hopkins Universität. Stand: 16.04.2020. 17:46 Uhr https://coronavirus.jhu.edu/map.html; https://github.com/CSSEGISandData/COVID-19/blob/ master/csse_covid_19_data/csse_covid_19_time_series/time_series_covid19_deaths_global.csv 


\section{Covid-19-Chronik, 30. Januar - 29. März 2020}

\begin{tabular}{|c|c|c|}
\hline Datum & $\begin{array}{l}\text { Offiziell bestä- } \\
\text { tigte Covid- } \\
\text { 19-Fälle in } \\
\text { Russland* }\end{array}$ & Ereignis \\
\hline 30.01 .2020 & k. A. & $\begin{array}{l}\text { Die russische Eisenbahngesellschaft gibt bekannt, dass der Personenzugverkehr zwischen } \\
\text { China und Russland bis zum 31. März } 2020 \text { ausgesetzt wird. Grund für diese Entschei- } \\
\text { dung ist der Ausbruch der Coronavirus-Epidemie, die ihr Epizentrum in der chinesischen } \\
\text { Stadt Wuhan hat. }\end{array}$ \\
\hline 31.01 .2020 & k. A. & $\begin{array}{l}\text { Die Vizeministerpräsidentin Tatjana Golikowa gibt bekannt, dass Russland den Flugverkehr } \\
\text { mit China ab dem 1. Februar } 2020 \text { aussetzen wird. Die Aussetzung betrifft fast den gesam- } \\
\text { ten Flugverkehr mit Ausnahme einiger regelmäßiger Flüge in die Städte Peking, Shanghai, } \\
\text { Guangzhou und Hongkong. Grund für diese Entscheidung ist der Ausbruch der Corona- } \\
\text { virus-Epidemie, die ihr Epizentrum in der chinesischen Stadt Wuhan hat. }\end{array}$ \\
\hline 01.02 .2020 & k. A. & $\begin{array}{l}\text { Die Regierung der Russischen Föderation ordnet an, das Abkommen über visumsfreies Rei- } \\
\text { sen zwischen Russland und China vorübergehend auszusetzen. Diese Maßnahme wird mit } \\
\text { der Verhinderung der Ausbreitung des Coronavirus begründet. Die Ausstellung von Arbeits- } \\
\text { visa für chinesische Staatsbürger wird vorübergehend ausgesetzt. Außerdem wird der Grenz- } \\
\text { übertritt chinesischer Staatsbürger an bestimmten Abschnitten der Staatsgrenze zwischen } \\
\text { Russland und der Mongolei eingeschränkt. }\end{array}$ \\
\hline 03.02 .2020 & k. A. & $\begin{array}{l}\text { Etwa } 130 \text { russische Staatsbürger, die sich in der chinesischen Provinz Hubei befinden, werden } \\
\text { von der russischen Luftwaffe nach Russland ausgeflogen. In Hubei liegt die Stadt Wuhan, } \\
\text { die Epizentrum der Coronavirus-Epidemie ist. }\end{array}$ \\
\hline 06.02 .2020 & k. A. & $\begin{array}{l}\text { Der Kreml beginnt die Temperatur von Veranstaltungsteilnehmern zu messen, die auf Prä- } \\
\text { sident Putin treffen. Dies sei eine Vorsichtsmaßnahme, so Sprecher Dmitri Peskow. }\end{array}$ \\
\hline 12.02 .2020 & k. A. & $\begin{array}{l}\text { In Tschita wird ein chinesischer Staatsbürger nach der Genesung von Covid-19 aus dem } \\
\text { Krankenhaus entlassen. Es ist der zweite bestätigte Fall einer Genesung nach einer Anste- } \\
\text { ckung mit dem Coronavirus. }\end{array}$ \\
\hline 19.02 .2020 & k. A. & $\begin{array}{l}144 \text { Menschen haben in Tjumen eine 14-tägige Quarantäne verlassen, nachdem sie aus } \\
\text { Wuhan in China, dem Epizentrum des Coronavirus-Ausbruchs, nach Russland evakuiert } \\
\text { worden waren. }\end{array}$ \\
\hline 20.02 .2020 & k. A. & $\begin{array}{l}\text { Der Nachrichtenwebseite RBC zufolge gibt der Finanzminister Anton Siluanow bekannt, } \\
\text { dass das Coronavirus einen Einbruch im chinesisch-russischen Handel im Umfang von einer } \\
\text { Milliarde Rubel (umgerechnet rund 14,5 Millionen Euro) pro Tag verursacht. }\end{array}$ \\
\hline 20.02 .2020 & k. A. & $\begin{array}{l}\text { Bei zwei russischen Staatsbürgern, die sich auf dem außerhalb Russlands in Quarantäne lie- } \\
\text { gendem Kreuzfahrtschiff Diamond Princess befinden, wird das Coronavirus diagnostiziert. } \\
\text { Damit steigt die Gesamtzahl der infizierten russischen Staatsbürger auf 3. }\end{array}$ \\
\hline 20.02 .2020 & k. A. & $\begin{array}{l}\text { Die Grenzschließung für chinesische Staatsbürger tritt in Kraft. Sie dürfen auf bestimmte } \\
\text { Zeit die Grenze zu Russland zum Zweck von Beschäftigung, Lehre, Tourismus und priva- } \\
\text { ten Reisen nicht mehr passieren. }\end{array}$ \\
\hline 21.02 .2020 & k. A. & $\begin{array}{l}\text { Ca. } 2.500 \text { Menschen, die aus China nach Russland eingereist sind, werden aufgrund der } \\
\text { Coronavirus-Epidemie in Moskau zur Quarantäne verpflichtet und mit einer Gesichtser- } \\
\text { kennungssoftware überwacht, so Moskaus Bürgermeister Sergej Sobjanin. }\end{array}$ \\
\hline 26.02 .2020 & k. A. & $\begin{array}{l}\text { Die stellvertretende Ministerpräsidentin Tatjana Golikowa gibt bekannt, dass ab dem } \\
\text { 28. Februar } 2020 \text { die Ausstellung von russischen Visa für iranische Staatsbürger ausgesetzt } \\
\text { wird. Außerdem wird ab dem 1. März } 2020 \text { der Flugverkehr mit Südkorea eingeschränkt. } \\
\text { Mit Ausnahme der Fluglinien "Aeroflot« und »Aurora«, die aus dieser Destination nur noch } \\
\text { den Moskauer Flughafen Scheremetjewo bedienen, wird es keine Flüge mehr in Richtung } \\
\text { und aus Südkorea nach Russland geben. Golikowa begründet diese Maßnahmen mit der } \\
\text { Ausbreitung des Coronavirus im Iran und in Südkorea. }\end{array}$ \\
\hline
\end{tabular}




\begin{tabular}{|c|c|c|}
\hline Datum & $\begin{array}{l}\text { Offiziell bestä- } \\
\text { tigte Covid- } \\
\text { 19-Fälle in } \\
\text { Russland* }\end{array}$ & Ereignis \\
\hline 27.02 .2020 & k. A. & $\begin{array}{l}\text { Moskaus Behörden haben } 88 \text { Personen identifizier, die gegen die Selbstisolationsvorschriften } \\
\text { der Stadt verstoßen haben, nachdem sie aus China zurückgekehrt waren, so Bürgermeister } \\
\text { Sobjanin. Die Stadt Moskau hat ihr Gesichtserkennungsnetzwerk zur Verfügung gestellt, } \\
\text { um die Quarantänemaßnahmen durchzusetzen. }\end{array}$ \\
\hline 28.02 .2020 & k. A. & $\begin{array}{l}\text { Moskaus Behörden weisen } 88 \text { ausländische Staatsbürger aus, die zuvor gegen Quarantäne- } \\
\text { maßnahmen verstoßen haben. Diese wurden verhängt, um der Ausbreitung des Corona- } \\
\text { virus vorzubeugen. }\end{array}$ \\
\hline 01.03 .2020 & 2 & \\
\hline 02.03 .2020 & 3 & \\
\hline 04.03 .2020 & 3 & $\begin{array}{l}\text { Russland hat zeitweise den Export von medizinischen Mundschutzmasken, Handschuhen, } \\
\text { Verbandsmaterial und Schutzanzügen verboten. }\end{array}$ \\
\hline 04.03 .2020 & 3 & $\begin{array}{l}\text { Präsident Putin fordert die Regierung auf, dafür zu sorgen, dass die Bevölkerung korrekt } \\
\text { über die Situation im Land informiert wird, denn es werden Fake News über das Corona- } \\
\text { virus aus dem Ausland in Russland verbreitet, um Panik unter der Bevölkerung zu schüren. }\end{array}$ \\
\hline 05.03 .2020 & 4 & $\begin{array}{l}\text { Das jährliche Internationale Wirtschaftsforum St. Petersburg wird vorsorglich wegen der } \\
\text { Coronavirus-Epidemie abgesagt. }\end{array}$ \\
\hline 05.03 .2020 & 4 & $\begin{array}{l}\text { Auf Anraten des Gesundheitsministeriums, Vorsichtsmaßnahmen gegen Covid-19 vorzu- } \\
\text { nehmen, beginnen russische Unternehmen Dienstreisen ins Ausland abzusagen. }\end{array}$ \\
\hline 06.03 .2020 & 13 & $\begin{array}{l}\text { Der russischen Verbraucherschutzbehörde (Abk. Rospotrebnadsor) zufolge haben russische } \\
\text { Behörden landesweit über } 51.000 \text { Tests auf Covid-19 durchgeführt. }\end{array}$ \\
\hline 06.03 .2020 & 13 & $\begin{array}{l}\text { Moskaus Bürgermeister Sergej Sobjanin hat die »erhöhte Alarmbereitschaft« für die Stadt } \\
\text { ausgerufen und die Selbstisolation für russische Staatsbürger, die aus China, Südkorea, den } \\
\text { Iran, Frankreich, Deutschland, Italien und Spanien zurückkehren, verordnet. }\end{array}$ \\
\hline 07.03 .2020 & 13 & \\
\hline 08.03 .2020 & 17 & $\begin{array}{l}\text { Moskaus Stadtverwaltung hat die Freiheitsstrafe für Menschen, die der zweiwöchigen häusli- } \\
\text { chen Selbstisolation nach einem Auslandsaufenthalt in von Covid-19 stark getroffenen Län- } \\
\text { dern nicht nachkommen, auf bis zu fünf Jahre angehoben. }\end{array}$ \\
\hline 09.03 .2020 & 17 & \\
\hline 10.03 .2020 & 20 & $\begin{array}{l}\text { Der Moskauer Bürgermeister Sergej Sobjanin verbietet ab 01. April } 2020 \text { per Dekret das } \\
\text { Abhalten von Veranstaltungen mit mehr als } 5.000 \text { Teilnehmern. Der Erlass gilt zunächst bis } \\
\text { zum 10. April 2020. Mit der Entscheidung soll die weitere Ausbreitung des Corona-Virus } \\
\text { in Moskau verhindert werden. }\end{array}$ \\
\hline 10.03 .2020 & 20 & $\begin{array}{l}\text { Der Rubel fällt erstmals seit vier Jahren auf das Niveau von März 2016. Damals brach der } \\
\text { Ölmarkt aufgrund des Scheiterns des OPEC-Vertrags zur Reduzierung der weltweiten Ölför- } \\
\text { derung zusammen. Der Kurs liegt bei Eröffnung des Handels bei 82,50 Rubel je } 1 \text { Euro. Der } \\
\text { Rubelverfall ist verbunden mit der Sorge des Marktes vor der Ausbreitung des Corona-Virus } \\
\text { und mit dem am Vortag eröffneten Preiskampf auf dem Ölmarkt, ausgelöst durch die Erhö- } \\
\text { hung der Ölfördermenge durch Saudi-Arabien vor dem Hintergrund geringer Nachfrage. }\end{array}$ \\
\hline 11.03 .2020 & 20 & $\begin{array}{l}\text { Russland setzt aufgrund der Ausbreitung des Corona-Virus in Italien vorübergehend die } \\
\text { Ausstellung von Visa für italienische Staatsbürger aus. Das Verbot gilt ab dem 13. März } \\
\text { 2020. Außerdem wird der Flugverkehr von und nach Italien, Deutschland, Frankreich und } \\
\text { Spanien bis auf wenige Ausnahmen eingestellt. }\end{array}$ \\
\hline 12.03 .2020 & 28 & $\begin{array}{l}\text { Der Gouverneur der Region Moskau ruft aufgrund von Covid-19 die »erhöhte Alarmbe- } \\
\text { reitschaft« aus und verbietet alle Veranstaltungen mit mehr als } 5.000 \text { Teilnehmern. Zudem } \\
\text { ruft er Unternehmen dazu auf, den Mitarbeitern das Home-Office zu gestatten. Dieser Auf- } \\
\text { ruf gilt nicht für die Stadt Moskau. }\end{array}$ \\
\hline 13.03 .2020 & 45 & $\begin{array}{l}\text { Die Stadt St. Petersburg und die Region Leningrad verbieten Veranstaltungen mit mehr } \\
\text { als } 1.000 \text { Teilnehmern. }\end{array}$ \\
\hline
\end{tabular}




\begin{tabular}{|c|c|c|}
\hline Datum & $\begin{array}{l}\text { Offiziell bestä- } \\
\text { tigte Covid- } \\
\text { 19-Fälle in } \\
\text { Russland* }\end{array}$ & Ereignis \\
\hline 13.03 .2020 & 45 & $\begin{array}{l}\text { Russland schließt vorübergehend seine Grenzen für italienische Staatsbürger und Men- } \\
\text { schen, die aus Italien einreisen, da Italien am stärksten von der Covid-19-Pandemie in } \\
\text { Europa betroffen ist. }\end{array}$ \\
\hline 14.03 .2020 & 59 & $\begin{array}{l}\text { Als Reaktion auf die weitere Ausbreitung des Corona-Virus in Moskau stellt der Moskauer } \\
\text { Bürgermeister Sergej Sobjanin es Eltern schulpflichtiger Kinder per Erlass ab sofort frei, diese } \\
\text { in die Schule zu schicken. Der Unterricht werde regulär fortgesetzt, die Schulpflicht jedoch } \\
\text { entfalle. Das russische Bildungsministerium empfiehlt derweil den regionalen Behörden die } \\
\text { Schließung von Schulen und die Durchführung des Unterrichts mit digitalen Hilfsmitteln. }\end{array}$ \\
\hline 14.03 .2020 & 59 & $\begin{array}{l}\text { Ministerpräsident Michail Mischustin teilt mit, dass Russland die Grenzen zu Polen und } \\
\text { Norwegen für Ausländer schließen wird, um die Ausbreitung des Corona-Virus zu begrenzen. }\end{array}$ \\
\hline 15.03 .2020 & 63 & $\begin{array}{l}\text { Der russische Präsident Wladimir Putin ordnet die Bildung einer Arbeitsgruppe des Staats- } \\
\text { rates zur Bekämpfung des Coronavirus an. Den Vorsitz soll Moskaus Bürgermeister Ser- } \\
\text { gej Sobjanin übernehmen. }\end{array}$ \\
\hline 15.03 .2020 & 63 & $\begin{array}{l}\text { Die russische Verbraucherschutzbehörde (Abk. Rospotrebnadsor) teilt mit, dass bereits über } \\
104.000 \text { Tests auf Covid-19 seit dem Beginn des Ausbruchs der Pandemie durchgeführt } \\
\text { wurden, während } 14.742 \text { Menschen gegenwärtig unter Beobachtung stünden. }\end{array}$ \\
\hline 16.03 .2020 & 90 & $\begin{array}{l}\text { Aufgrund der Ausbreitung des Coronavirus zeichnet der staatliche Fernsehkanal »Perwyj } \\
\text { kanal» (dt. "Erster Kanal») ab sofort Sendungen ohne Zuschauer auf. }\end{array}$ \\
\hline 16.03 .2020 & 90 & $\begin{array}{l}\text { Der russische Ministerpräsident Michail Mischustin kündigt die Einrichtung eines Anti- } \\
\text { Krisen-Fonds in Höhe von } 300 \text { Milliarden Rubel (etwa 3,6 Milliarden Euro) an, zur Unter- } \\
\text { stützung der Industrie und der Bevölkerung vor dem Hintergrund der Ausbreitung des } \\
\text { Coronavirus. Außerdem habe der neu gegründete Koordinationsrat die Einrichtung einer } \\
\text { Hotline und eines Online-Warnsystems als Sofortmaßnahmen beschlossen. Mischustin } \\
\text { steht dem Koordinationsrat vor. }\end{array}$ \\
\hline 16.03 .2020 & 90 & $\begin{array}{l}\text { Russland schließt mit sofortiger Wirkung seine Grenze zu Belarus. Dies gab der russische } \\
\text { Ministerpräsident Michail Mischustin bekannt. Er begründete diese Maßnahme mit dem } \\
\text { Kampf gegen das neuartige Coronavirus. Seit dem 16. März } 2020 \text { sind außerdem die rus- } \\
\text { sischen Grenzen zu Georgien geschlossen. }\end{array}$ \\
\hline 16.03 .2020 & 90 & $\begin{array}{l}\text { Der Moskauer Bürgermeister Sergej Sobjanin verbietet per Dekret ab sofort alle Veranstal- } \\
\text { tungen im Freien sowie alle Veranstaltungen mit mehr als } 50 \text { Teilnehmern in geschlossenen } \\
\text { Räumen. Außerdem verkündet er die Schließung aller Moskauer Schulen ab dem 21. März } \\
2020 \text { für drei Wochen. Die dreiwöchige Schließung von Schulen ab dem 23. März } 2020 \\
\text { wird außerdem auch in der Region Moskau angekündigt. }\end{array}$ \\
\hline 16.03 .2020 & 90 & $\begin{array}{l}\text { Die russische Regierung gibt bekannt, dass die Einreise von ausländischen Staatsbürgern } \\
\text { und Staatenlosen ab dem 18. März } 2020 \text { als Reaktion auf die Ausbreitung der Covid-19- } \\
\text { Pandemie untersagt ist. Von der Regelung ausgeschlossen sind u. a. Mitarbeiter diplomat- } \\
\text { scher Dienste und Crewmitarbeit im Flugverkehr. }\end{array}$ \\
\hline 16.03 .2020 & 90 & $\begin{array}{l}\text { Nach einer Einreise aus den Vereinigten Staaten und Europa, darunter auch Ukraine und } \\
\text { Belarus, gilt für die Einreisenden als auch für ihre Mitbewohner eine 14-tägige Quaran- } \\
\text { täne in Selbstisolation ab Ankunft. }\end{array}$ \\
\hline 16.03 .2020 & 90 & $\begin{array}{l}\text { Die städtische Gesundheitsbehörde in St. Petersburg gibt bekannt, dass ab heute jeder in } \\
\text { der Stadt einen Covid-19-Tests bekommen könnte. }\end{array}$ \\
\hline 17.03 .2020 & 114 & $\begin{array}{l}\text { Das Kulturministerium der Russischen Föderation gibt wegen der Ausbreitung des Coro- } \\
\text { navirus die vorübergehende Schließung aller ihm unterstehenden öffentlichen Kulturein- } \\
\text { richtungen bekannt. Dies betrifft unter anderem Theater, Museen und Kinos. }\end{array}$ \\
\hline 17.03 .2020 & 114 & $\begin{array}{l}\text { Wegen der Ausbreitung des Coronavirus werden die Grenzübergänge von der Krim zur } \\
\text { Ukraine zunächst bis zum 18. Mai } 2020 \text { geschlossen. Dies teilte der Pressedienst des Grenz- } \\
\text { schutzes des Russischen Föderalen Sicherheitsdienstes (FSB) mit. }\end{array}$ \\
\hline
\end{tabular}




\begin{tabular}{|c|c|c|}
\hline Datum & $\begin{array}{l}\text { Offiziell bestä- } \\
\text { tigte Covid- } \\
\text { 19-Fälle in } \\
\text { Russland* }\end{array}$ & Ereignis \\
\hline 17.03 .2020 & 114 & $\begin{array}{l}\text { Die russische Verbraucherschutzbehörde (Abk. Rospotrebnadsor) hat den Regionen ange- } \\
\text { ordnet, jeden auf Covid-19 zu testen, der sich in den vergangenen zwei Wochen im euro- } \\
\text { päischen Ausland aufgehalten hat. }\end{array}$ \\
\hline 18.03 .2020 & 147 & $\begin{array}{l}\text { Der russische Bildungsminister Sergej Krawzow gibt bekannt, dass wegen der Ausbreitung } \\
\text { des Coronavirus mit Wirkung zum 23. März } 2020 \text { bis voraussichtlich } 12 \text {. April } 2020 \text { alle } \\
\text { russischen Schulen geschlossen werden. Der Unterricht solle mit Hilfe digitaler Medien } \\
\text { gewährleistet werden. }\end{array}$ \\
\hline 18.03 .2020 & 147 & $\begin{array}{l}\text { Moskaus Polizeichef Oleg Baranow teilt mit, dass das städtische Netzwerk von Kameras } \\
\text { zur Gesichtserkennung bereits mehr als } 200 \text { Personen ausfindig gemacht hat, die gegen die } \\
\text { Selbstisolationsverordnung wegen einer möglichen Infektion mit dem Coronavirus versto- } \\
\text { ßen haben. }\end{array}$ \\
\hline 19.03 .2020 & 199 & $\begin{array}{l}\text { Russland beginnt mit der Rückholaktion russischer Staatsbürger aus Montenegro. Monte- } \\
\text { negro hatte als Maßnahme gegen eine weitere Verbreitung des Coronavirus am 16. März } \\
2020 \text { seine Grenzen geschlossen und den internationalen Flugverkehr eingestellt. }\end{array}$ \\
\hline 19.03 .2020 & 199 & $\begin{array}{l}\text { Ein Sprecher der städtischen Moskauer Gerichte gibt bekannt, dass das laufende Gerichts- } \\
\text { verfahren gegen Mitarbeiter der Sicherheitsbehörden im Fall des im Juni } 2019 \text { inhaftierten } \\
\text { Journalisten Iwan Golunow sowie das laufende Verfahren gegen die von Regisseur Kirill } \\
\text { Serebrennikow gegründete gemeinnützige Organisation "Sedmaja Studija» (dt. "Siebtes } \\
\text { Studio«) ab sofort unter Ausschluss der Öffentlichkeit staatfindet. Begründet wird dieser } \\
\text { Schritt mit Präventionsmaßnahmen gegen die Ausbreitung des Coronavirus sowie mit der } \\
\text { Dringlichkeit der Fälle, die ein Verschieben der geplanten Sitzungen nach dem 10. April } \\
2020 \text { nicht möglich machen. }\end{array}$ \\
\hline 19.03 .2020 & 199 & $\begin{array}{l}\text { Die Gerichte in Russland werden ab den 24. März bis zum 10. April alle laufenden Gerichts- } \\
\text { verfahren aussetzen, um die Ausbreitung von Covid-19 einzudämmen. Ausgenommen davon } \\
\text { sind die dringendsten Verfahren. Dies hatte das Oberste Gericht einen Tag zuvor entschieden. }\end{array}$ \\
\hline 19.03 .2020 & 199 & $\begin{array}{l}\text { In einem Moskauer Krankenhaus verstirbt eine } 79 \text {-jährige Frau, die zuvor positiv auf Covid- } \\
19 \text { getestet wurde. Es ist der erste Todesfall in Russland, der im Zusammenhang mit dem } \\
\text { Covid-19-Virus steht. }\end{array}$ \\
\hline 19.03 .2020 & 199 & $\begin{array}{l}\text { Die russische Regierung ruft die "erhöhte Alarmbereitschaft« in allen } 85 \text { Regionen aus und } \\
\text { fordert das ganze Land dazu auf, Maßnahmen gegen das Covid-19-Virus vorzunehmen } \\
\text { wie das Verbot größerer Veranstaltungen, Heim- und Onlineunterricht und die Aufforde- } \\
\text { rung zur Heimarbeit. }\end{array}$ \\
\hline 19.03 .2020 & 199 & $\begin{array}{l}\text { Die russische Verbraucherschutzbehörde (Abk. Rospotrebnadsor) hat allen Einreisenden } \\
\text { eine verpflichtende zweiwöchige häusliche Selbstisolation verordnet, auch wenn diese keine } \\
\text { Symptome von Covid-19 zeigen. }\end{array}$ \\
\hline 20.03 .2020 & 253 & $\begin{array}{l}\text { Die Musterungen für den Grundwehrdienst in den russischen Streitkräften im Frühling } \\
\text { werden ungeachtet der Covid-19-Pandemie wie geplant stattfinden, sagt Verteidigungsmi- } \\
\text { nister Sergej Schojgu. Alle neuen Rekruten werden auf das Virus getestet. }\end{array}$ \\
\hline 20.03 .2020 & 253 & $\begin{array}{l}\text { Die Leiterin für den Infektionsschutz der Region Stavropol ist nach einer Reise nach Spa- } \\
\text { nien mit Verdacht auf das Coronavirus in das örtliche Krankenhaus eingeliefert worden. } \\
\text { Sie hat trotz Symptome ihre Arbeit angetreten. }\end{array}$ \\
\hline 21.03 .2020 & 306 & $\begin{array}{l}\text { Russland beginnt mit der Auslieferung von Covid-19-Schnelltests an Länder der Eurasischen } \\
\text { Wirtschaftsunion, der GUS sowie an den Iran, die Mongolei sowie Nordkorea. Geplant sind } \\
\text { auch Lieferungen an Ägypten, Serbien und Venezuela. Ministerpräsident Michail Mischus- } \\
\text { tin bestätigte zuvor, dass Russland einen Bestand von } 700.000 \text { Tests habe, der ständig auf- } \\
\text { gefüllt würde. }\end{array}$ \\
\hline 21.03 .2020 & 306 & $\begin{array}{l}\text { Die Zahl gemeldeter Covid-19-Erkrankungen erhöhte sich in den vergangenen } 24 \text { Stunden } \\
\text { um } 53 \text { auf insgesamt } 306 \text { in } 18 \text { Regionen Russlands. Besonders betroffen ist mit } 137 \text { gemel- } \\
\text { deten Fällen die Hauptstadt Moskau. }\end{array}$ \\
\hline
\end{tabular}




\begin{tabular}{|c|c|c|}
\hline Datum & $\begin{array}{l}\text { Offiziell bestä- } \\
\text { tigte Covid- } \\
\text { 19-Fälle in } \\
\text { Russland* }\end{array}$ & Ereignis \\
\hline 21.03 .2020 & 306 & $\begin{array}{l}\text { In Moskau schließen aufgrund der Ausbreitung des Coronavirus Fitnessstudios und } \\
\text { Schwimmbäder. }\end{array}$ \\
\hline 21.03 .2020 & 306 & $\begin{array}{l}\text { Russland fliegt russische Staatsbürger aus der moldawischen Hauptstadt Chisinau aus. In } \\
\text { Moldawien gilt seit dem 17. März der Ausnahmezustand aufgrund der Ausbreitung des } \\
\text { Coronavirus. Der Flugverkehr ist vollständig eingestellt, die Grenzen sind geschlossen. }\end{array}$ \\
\hline 22.03 .2020 & 367 & $\begin{array}{l}\text { Die Zahl der offiziell gemeldeten Corvid-19-Erkrankungen stieg in den vergangenen } 24 \text { Stun- } \\
\text { den um } 61 \text { auf insgesamt 367. In Moskau sind es bisher insgesamt } 191 \text { Fälle und damit } 54 \\
\text { mehr als noch am 21.03.2020. Laut offfiziellen Angaben seien alle neu erkrankten Patienten } \\
\text { in den vergangenen zwei Wochen aus Risikogebieten im Ausland zurückgekehrt. }\end{array}$ \\
\hline 22.03 .2020 & 367 & $\begin{array}{l}\text { In einer Stellungnahme gibt das russische Verteidigungsministerium bekannt, dass das rus- } \\
\text { sische Militär nach einem erfolgten Befehl des Präsidenten Putin ab Sonntag damit begin- } \\
\text { nen wird, medizinische Hilfe nach Italien zu schicken, um dem Land bei der Bekämpfung } \\
\text { des Coronavirus zu helfe. }\end{array}$ \\
\hline 23.03 .2020 & 438 & $\begin{array}{l}\text { Die russische Regierung stellt mehr als } 23 \text { Milliarden Rubel (etwa } 266 \text { Millionen Euro) für } \\
\text { die Herstellung von medizinischen und pharmazeutischen Produkten bereit. Dies erklärte } \\
\text { der russische Ministerpräsident Michail Mischustin bei einem Treffen mit seinen Stellver- } \\
\text { tretern. Die Mittel werden über den Fonds für industrielle Entwicklung finanziert und sol- } \\
\text { len vor allem zur Anschaffung von Infrarotkameras, kontaktlosen Fieberthermometern und } \\
\text { Luftdesinfektionsgeräten genutzt werden. }\end{array}$ \\
\hline 23.03 .2020 & 438 & $\begin{array}{l}\text { Der Moskauer Bürgermeister Sergej Sobjanin fordert im Kampf gegen die Ausbreitung des } \\
\text { Coronavirus alle Einwohner Moskaus im Alter von über } 65 \text { Jahren auf, zuhause zu bleiben. } \\
\text { Diese Anordnung gelte ab dem 26. März und zunächst bis voraussichtlich } 14 \text {. April } 2020 . \\
\text { Sobjanin fordert darin ausdrücklich, auch der Arbeit fernzubleiben, sofern die Anwesenheit } \\
\text { am Arbeitsplatz für das Unternehmen nicht von entscheidender Bedeutung sei. Lebensmit- } \\
\text { teleinkauf und das Aufsuchen von Apotheken ist bei vorliegender Notwendigkeit gestat- } \\
\text { tet. Darüber hinaus verpflichtete er Telekommunikationsdienstleister, die Bürger auch bei } \\
\text { Zahlungsverzug weiter mit Telekommunikationsdienstleistungen zu versorgen. Bußgelder } \\
\text { für verspätete Mietzahlungen werden ausgesetzt. } \\
\text { Später teilt der Kreml mit, dass die häusliche Selbstisolation für Menschen über } 65 \text { Jahren } \\
\text { nicht für den Präsidenten gelte, der } 67 \text { Jahre alt ist. }\end{array}$ \\
\hline 23.03 .2020 & 438 & $\begin{array}{l}\text { Die Zahl der offiziell gemeldeten Covid-19-Infektionen ist in Russland in den vergange- } \\
\text { nen } 24 \text { Stunden um } 71 \text { auf insgesamt } 438 \text { gestiegen. Alle neuen Infektionsfälle beschrän- } \\
\text { ken sich auf das Moskauer Stadtgebiet. }\end{array}$ \\
\hline 23.03 .2020 & 438 & $\begin{array}{l}\text { Nachdem das siebte Krankenhaus für die Behandlung von Covid-19-Patienten umgewan- } \\
\text { delt worden ist, teilt Moskaus Bürgermeister Sergej Sobjanin mit, dass die städtischen Kapa- } \\
\text { zitäten dieses Vorgehen bei Bedarf mehr als verdoppeln könnten. }\end{array}$ \\
\hline 24.03 .2020 & 495 & $\begin{array}{l}\text { Die Zahl offiziell gemeldeter Covid-19-Infektionen ist in Russland innerhalb der vergange- } \\
\text { nen } 24 \text { Stunden um } 57 \text { auf insgesamt } 495 \text { gestiegen. Gemeldet wurden Infektionen aus } 14 \\
\text { Regionen Russlands. Die meisten Fälle gibt es in den Städten Moskau und Sankt Petersburg. }\end{array}$ \\
\hline 24.03 .2020 & 495 & $\begin{array}{l}\text { In der autonomen Republik Tschetschenien gibt es eine erste bestätigte Covid-19-Infektion. } \\
\text { Präsident Ramsan Kadyrow ruft die Einwohner Tschetscheniens auf, zuhause zu bleiben. } \\
\text { Er kündigt die Schließung aller Restaurants, Cafés und sonstiger Versammlungsorte an. }\end{array}$ \\
\hline 24.03 .2020 & 495 & $\begin{array}{l}\text { Die russische Fluggesellschaft »Aeroflot« kündigt an, aufgrund der Covid-19-Pandemie ihre } \\
\text { regelmäßigen Flüge nach Vietnam, Thailand, in die Türkei, die Vereinigten Arabischen Emi- } \\
\text { rate sowie nach Kuba bis zum 30. April } 2020 \text { einzuschränken. }\end{array}$ \\
\hline 24.03 .2020 & 495 & $\begin{array}{l}\text { Anastasija Rakowa, stellvertretende Bürgermeisterin der Stadt Moskau, gibt bekannt, dass } \\
\text { die städtischen Krankenhäuser für die Behandlung von mit Covid-19 infizierten Patien- } \\
\text { ten ab sofort bis zu } 200.000 \text { Rubel (etwa } 2.300 \text { Euro) aus dem Krankenversicherungsfonds } \\
\text { der Stadt erhalten. }\end{array}$ \\
\hline
\end{tabular}




\begin{tabular}{|c|c|c|}
\hline Datum & $\begin{array}{l}\text { Offiziell bestä- } \\
\text { tigte Covid- } \\
\text { 19-Fälle in } \\
\text { Russland* }\end{array}$ & Ereignis \\
\hline 24.03 .2020 & 495 & $\begin{array}{l}\text { In einem Video, das Präsident Putin und den Moskauer Bürgermeister Sergej Sobjanin zeigt, } \\
\text { teilt Sobjanin mit, dass Russland sich in einer »ernsten Situation« wegen des Coronavirus } \\
\text { befinde und dass die »tatsächlichen Zahlen der Erkrankten weitaus höher seien« als die offi- } \\
\text { ziell bekanntgegebenen Zahlen. }\end{array}$ \\
\hline 24.03 .2020 & 495 & $\begin{array}{l}\text { Putin besucht ein Krankenhaus in dem Moskauer Vorort Kommunarka, in dem Covid-19 } \\
\text { erkrankte Patienten stationär behandelt werden. }\end{array}$ \\
\hline 25.03 .2020 & 658 & $\begin{array}{l}\text { Die russische Verbraucherschutzbehörde (Abk. Rospotrebnadsor), bei der das epidemiologi- } \\
\text { sche Kontrollzentrum angesiedelt ist, erhält 1,4 Milliarden Rubel (etwa } 19 \text { Millionen Euro) } \\
\text { aus dem Reservefonds des Ministerkabinetts, für die Entwicklung von Mitteln zur Präven- } \\
\text { tion und Diagnostik im Zusammenhang mit dem Coronavirus. }\end{array}$ \\
\hline 25.03 .2020 & 658 & $\begin{array}{l}\text { Die Anzahl der offiziell gemeldeten Covid-19-Infektionen stieg in Russland innerhalb der } \\
\text { vergangenen } 24 \text { Stunden um } 163 \text { auf insgesamt 658. } 120 \text { der neuen Fälle wurden aus Mos- } \\
\text { kau gemeldet. Insgesamt } 55 \text { Regionen melden Infektionen. }\end{array}$ \\
\hline 25.03 .2020 & 658 & $\begin{array}{l}\text { Der Moskauer Bürgermeister Sergej Sobjanin verfügt aufgrund der Ausbreitung des Coro- } \\
\text { navirus die Schließung aller Kultur- und Freizeiteinrichtungen. Betroffen sind neben Bars, } \\
\text { Cafés und Restaurants z. B. auch Kinos, Diskotheken und Bibliotheken. }\end{array}$ \\
\hline 25.03 .2020 & 658 & $\begin{array}{l}\text { Der Covid-19-Koordinationsrat in Moskau gibt bekannt, dass zwei an Covid-19 erkrankte } \\
\text { Menschen im Alter von } 73 \text { und } 88 \text { Jahren verstorben sind. }\end{array}$ \\
\hline 25.03 .2020 & 658 & $\begin{array}{l}\text { Der russische Präsident Wladimir Putin wendet sich in einer Fernsehansprache an das rus- } \\
\text { sische Volk. Er fordert dazu auf, den Empfehlungen der Behörden hinsichtlich der Maß- } \\
\text { nahmen zur Eindämmung des Coronavirus zu folgen. Außerdem erklärt er die Woche vom } \\
28 \text {. März bis zum 05. April } 2020 \text { zur bazahlten arbeitsfreien Woche. Die für den 22. April } \\
2020 \text { anberaumte Volksabstimmung zur Verfassungsänderung wird auf unbestimmte Zeit } \\
\text { verschoben. }\end{array}$ \\
\hline 26.03 .2020 & 840 & $\begin{array}{l}\text { Der russische Ministerpräsident Michail Mischustin ordnet die Einstellung des internatio- } \\
\text { nalen Flugverkehrs von und nach Russland ab dem 27. März } 2020 \text { an. Ausgenommen hier- } \\
\text { von seien einzig Charterflüge zur Rückholung russischer Staatsbürger aus dem Ausland. }\end{array}$ \\
\hline 26.03 .2020 & 840 & $\begin{array}{l}\text { Der Moskauer Bürgermeister Sergej Sobjanin verfügt per Dekret die Schließung aller Ein- } \\
\text { zelhandelsgeschäfte der Stadt ab dem 28. März 2020. Ausgenommen sind Lebensmittel- } \\
\text { geschäfte und Apotheken. }\end{array}$ \\
\hline 26.03 .2020 & 840 & $\begin{array}{l}\text { Die Zahl offiziell gemeldeter Coronavirus-Infektionen in Russland ist innerhalb der vergan- } \\
\text { genen } 24 \text { Stunden um } 182 \text { auf insgesamt } 840 \text { gestiegen. } 136 \text { Neu-Infektionen gab es allein } \\
\text { in Moskau. Infektionen melden insgesamt } 56 \text { Regionen. }\end{array}$ \\
\hline 26.03 .2020 & 840 & $\begin{array}{l}\text { Die Region Moskau schließen Cafés und Restaurants mit Wirkung zum 28. März } 2020 \text { für } \\
\text { den Zeitraum von einer Woche. Auch die Stadt Sankt Petersburg gibt die Schließung von } \\
\text { Cafés und Restaurants sowie kirchlicher Einrichtungen vom 28. März bis zum 05. April } \\
2020 \text { bekannt. Außerdem werden bis zum 30. April } 2020 \text { alle Kultur- und Freizeiteinrich- } \\
\text { tungen geschlossen. }\end{array}$ \\
\hline 26.03 .2020 & 840 & $\begin{array}{l}\text { Der russische Präsident Wladimir Putin unterzeichnet ein Gesetz, das es der Regierung } \\
\text { ermöglicht, die Preise für Medikamente und medizinische Geräte im Fall einer Epidemie } \\
\text { zu regulieren. Das Gesetz war am 19. März } 2020 \text { von der Staatsduma verabschiedet und } \\
\text { am } 25 \text {. März } 2020 \text { vom Föderationsrat gebilligt worden. }\end{array}$ \\
\hline 26.03 .2020 & 840 & $\begin{array}{l}\text { Die Stadt Sotschi bittet die Moskauer darum, die Stadt während der arbeitsfreien Woche } \\
\text { zu meiden. }\end{array}$ \\
\hline 26.03 .2020 & 840 & $\begin{array}{l}\text { Ab dem 30. März wird Sberbank und die VTB mit Rückhalt der Zentralbank ein Pilot- } \\
\text { programm für Geschäftskredite für den Zeitraum von sechs Monaten zum 0\%-Zinssatz } \\
\text { anbieten, damit Unternehmen ihren Angestellten während der Coronavirus-Krise Löhne } \\
\text { zahlen können. }\end{array}$ \\
\hline
\end{tabular}




\begin{tabular}{|c|c|c|}
\hline Datum & $\begin{array}{l}\text { Offiziell bestä- } \\
\text { tigte Covid- } \\
\text { 19-Fälle in } \\
\text { Russland* }\end{array}$ & Ereignis \\
\hline 27.03 .2020 & 1.036 & $\begin{array}{l}\text { Der russische Ministerpräsident Michail Mischustin weist die regionalen Behörden an, die } \\
\text { Schließung von Cafés und Restaurants vom 28. März bis zum 05. April } 2020 \text { anzuordnen. } \\
\text { Außerdem werden touristische Einrichtungen wie Hotels, Sanatorien und Ferienlager bis } \\
\text { zum 01. Juni } 2020 \text { geschlossen bleiben. }\end{array}$ \\
\hline 27.03 .2020 & 1.036 & $\begin{array}{l}\text { Der regionale Krisenstab zur Kontrolle der Verbreitung des Coronavirus im Autonomen } \\
\text { Kreis der Tschuktschen fordert Menschen im Alter von über } 65 \text { Jahren und chronisch Kranke } \\
\text { auf, zuhause zu bleiben. Bisher gibt es im Autonomen Kreis der Tschuktschen keinen offi- } \\
\text { ziell bestätigten Infektionsfall. }\end{array}$ \\
\hline 27.03 .2020 & 1.036 & $\begin{array}{l}\text { Die Zahl offiziell gemeldeter Coronavirus-Infektionen in Russland ist innerhalb der vergan- } \\
\text { genen } 24 \text { Stunden um } 196 \text { auf insgesamt } 1.036 \text { gestiegen. } 157 \text { neue Fälle meldet allein Mos- } \\
\text { kau. Nach offiziellen Angaben sind vier Menschen einer Infektion mit dem Virus erlegen. }\end{array}$ \\
\hline 28.03 .2020 & 1.264 & $\begin{array}{l}\text { Der Generaldirektor der russischen Anti-Doping-Agentur (Rusada), Jurij Ganus, gibt } \\
\text { bekannt, dass die Dopingkontrollen russischer Athleten aufgrund der Ausbreitung des } \\
\text { Coronavirus vorerst ausgesetzt wurden. }\end{array}$ \\
\hline 28.03 .2020 & 1.264 & $\begin{array}{l}\text { Die Zahl offiziell gemeldeter Coronavirus-Infektionen in Russland ist innerhalb der ver- } \\
\text { gangenen } 24 \text { Stunden um } 228 \text { auf insgesamt } 1.264 \text { gestiegen. } 114 \text { neue Fälle wurden aus } \\
\text { Moskau gemeldet. Nach offiziellen Angaben gibt es bislang fünf Tote. }\end{array}$ \\
\hline 28.03 .2020 & 1.264 & $\begin{array}{l}\text { Die Regierung der autonomen Republik Tschetschenien gibt die Einschränkung der Rei- } \\
\text { sefreiheit für Einwohner der Hauptstadt Grosnyj bekannt. Magomed Daudow, Vorsitzen- } \\
\text { der des tschetschenischen Parlaments, gab an, dass es ab sofort verboten sei, den Ort sei- } \\
\text { nes festen Wohnsitzes zu verlassen. Außerdem gibt es Beschränkungen für eine Einreise in } \\
\text { die Stadt. In Tschetschenien gibt es bisher drei bestätigte Fälle von Covid-19-Infektionen. }\end{array}$ \\
\hline 28.03 .2020 & 1.264 & $\begin{array}{l}\text { In der autonomen Republik Kalmückien wird der Notstand aufgrund der Ausbreitung des } \\
\text { Coronavirus ausgerufen. Kultur- und Freizeiteinrichtungen werden vorübergehend geschlos- } \\
\text { sen, der öffentliche Personennachverkehr wird ausgesetzt. Außerdem wird allen Menschen } \\
\text { im Alter von über } 65 \text { Jahren empfohlen, zuhause zu bleiben. Bisher gibt es einen offiziell } \\
\text { bestätigten Infektionsfall in der Republik. }\end{array}$ \\
\hline 28.03 .2020 & 1.264 & $\begin{array}{l}\text { Ab dem 30. März schließt Russland alle seine Landes- und Seegrenzen, um die Verbreitung } \\
\text { des Coronavirus zu stoppen. }\end{array}$ \\
\hline 29.03 .2020 & 1.534 & $\begin{array}{l}\text { Der Moskauer Bürgermeister Sergej Sobjanin erlässt per Dekret eine Ausgangssperre für } \\
\text { alle Einwohner der Hauptstadt. Das Verlassen der Wohnung ist ab dem } 30 \text {. März } 2020 \\
\text { nur im medizinischen Notfall, für Einkäufe oder für eine unerlässliche Fahrt zur Arbeits- } \\
\text { stätte gestattet. Das Ausführen von Haustieren ist nur im Umkreis von } 100 \text { Metern um den } \\
\text { Wohnsitz erlaubt. Außerdem gilt verpflichtend die Einhaltung von mindestens eineinhalb } \\
\text { Metern Abstand zu anderen Menschen. }\end{array}$ \\
\hline 29.03 .2020 & 1.534 & $\begin{array}{l}\text { Der Gouverneur der Region Moskau, Andrej Worobjow, gibt bekannt, dass ab dem 30. März } \\
2020 \text { eine Ausgangssperre für das Gebiet gilt. Das Verlassen der Wohnung ist nur im medi- } \\
\text { zinischen Notfall, für Einkäufe oder für Fahrten zum Arbeitsplatz gestattet. Auch das Aus- } \\
\text { führen von Haustieren ist nur in einem Umkreis von } 100 \text { Metern zum Wohnsitz gestattet. }\end{array}$ \\
\hline 29.03 .2020 & 1.534 & $\begin{array}{l}\text { Die arbeitslos gemeldeten Einwohner der Stadt Moskau sowie der Region Moskau erhal- } \\
\text { ten ab dem 01. April } 2020 \text { eine monatliche Zahlung von } 19.500 \text { Rubel (etwa } 220 \text { Euro) in } \\
\text { der Hauptstadt sowie } 15.000 \text { Rubel (etwa } 170 \text { Euro) in der Region Moskau als sogenannte } \\
\text { Entschädigungszahlung. Dies gaben die zuständigen Behörden bekannt. }\end{array}$ \\
\hline 29.03 .2020 & 1.534 & $\begin{array}{l}\text { Die Zahl offiziell gemeldeter Coronavirus-Infektionen in Russland ist innerhalb der vergan- } \\
\text { genen } 24 \text { Stunden um } 270 \text { auf insgesamt } 1.534 \text { gestiegen. } 197 \text { neue Fälle wurden aus Mos- } \\
\text { kau gemeldet. Die Zahl der Toten liegt nach offiziellen Angaben derzeit bei acht. }\end{array}$ \\
\hline 29.03 .2020 & 1.534 & $\begin{array}{l}\text { Einer offiziellen Statistik zufolge sind } 40 \% \text { der Patienten, die infolge von Covid-19 mit Beat- } \\
\text { mungsgeräten beatmet werden, unter } 40 \text { Jahren. Ebenso sind } 15 \% \text { aller schwer erkrankten } \\
\text { in Moskau unter } 40 \text { Jahren alt. }\end{array}$ \\
\hline
\end{tabular}

* Quelle: Johns Hopkins Universität, Stand 29.03.2020

Zusammengestellt von Alena Schwarz 


\section{Coronavirus-Pandemie (20.-26 Februar und 19.-25. März 2020)}

Grafik 1: Haben Sie Angst davor, sich mit dem Coronavirus anzustecken? (eine Antwortnennung möglich) (20.-26 Februar und 19.-25. März 2020)

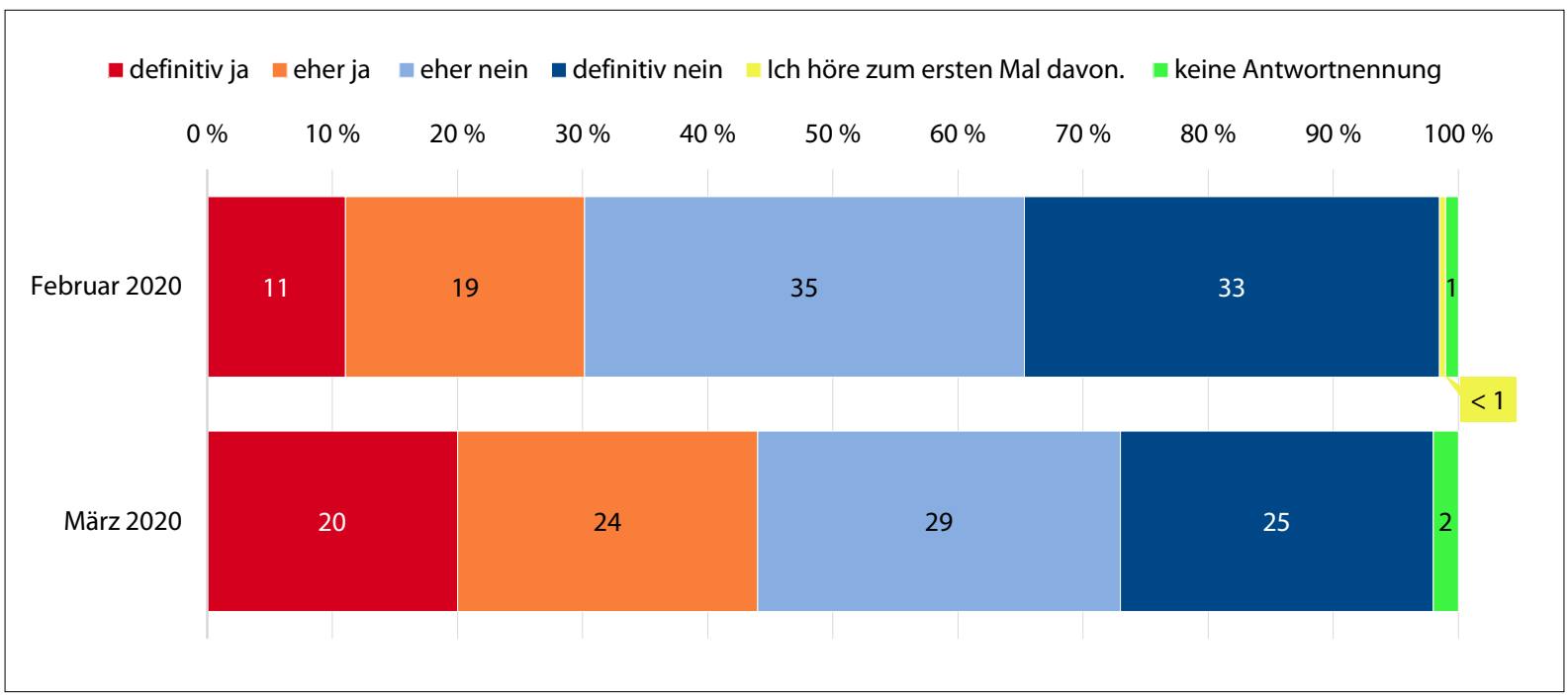

Quelle: repräsentative Umfrage des Lewada-Zentrums vom 19. - 25. März 2020, www.levada.ru/2020/03/26/pandemiya-koronavirusa/, veröffentlicht am 26.03.2020

Grafik 2: Was tun Sie, um sich vor einer Ansteckung zu schützen? (Anteil in \% der Befragten, die Angst davor haben, sich mit dem Coronavirus anzustecken. Den Befragten wurde eine Karte mit Antworten (im Rang absteigend) vorgelegt und sie konnten mehr als eine Antwort wählen.) (20.-26 Februar 2020)

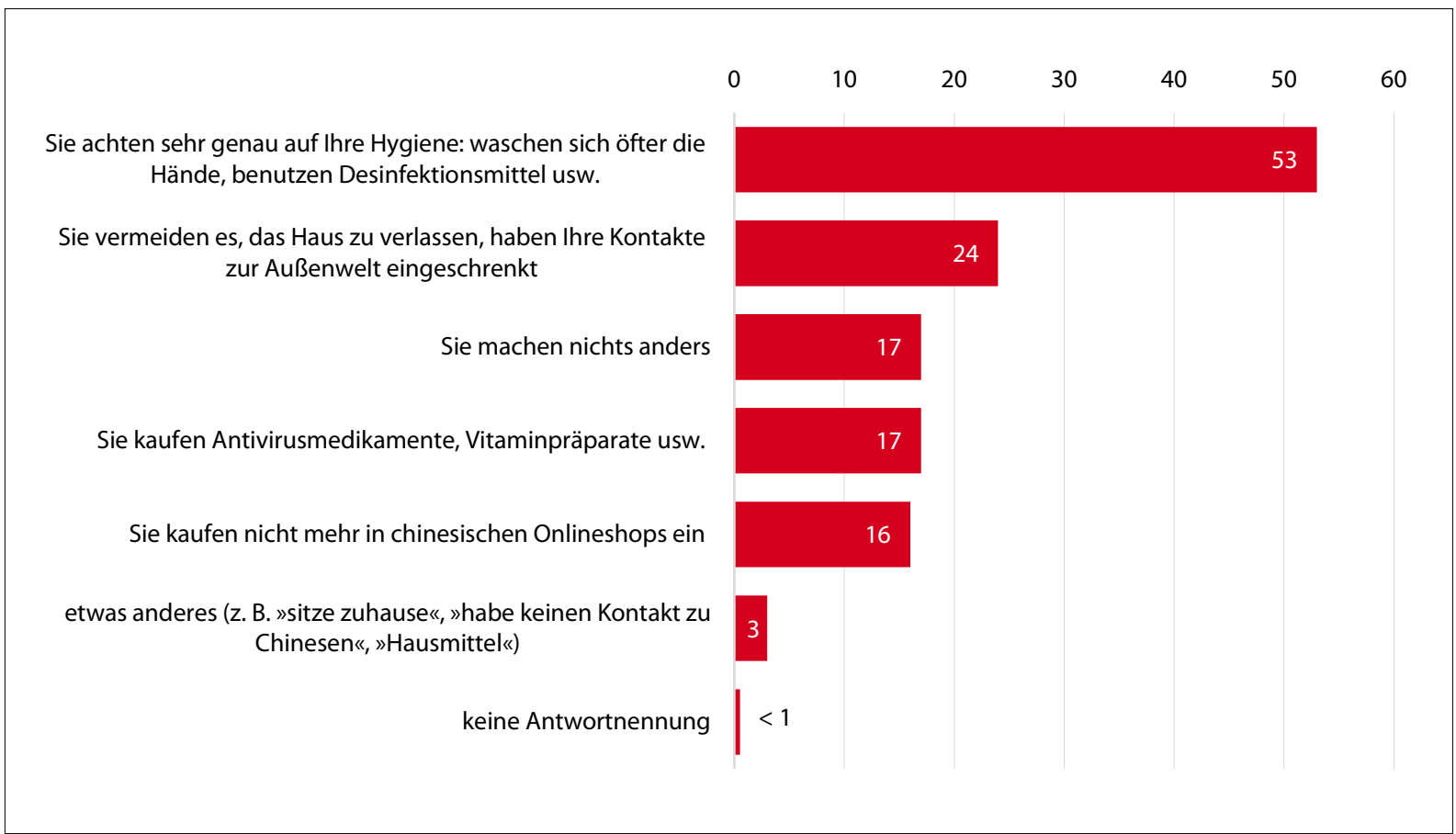

Quelle: repräsentative Umfrage des Lewada-Zentrums vom 20. - 26. Februar 2020, www.levada.ru/2020/03/02/koronavirus/, veröffentlicht am 02.03.2020 
Grafik 3: $\quad$ Mussten Sie im Zusammenhang mit der Verbreitung des Coronavirus ...? (Den Befragten wurde eine Karte mit Antworten (im Rang absteigend) vorgelegt und sie konnten mehr als eine Antwort wählen.) (19.-25. März 2020)

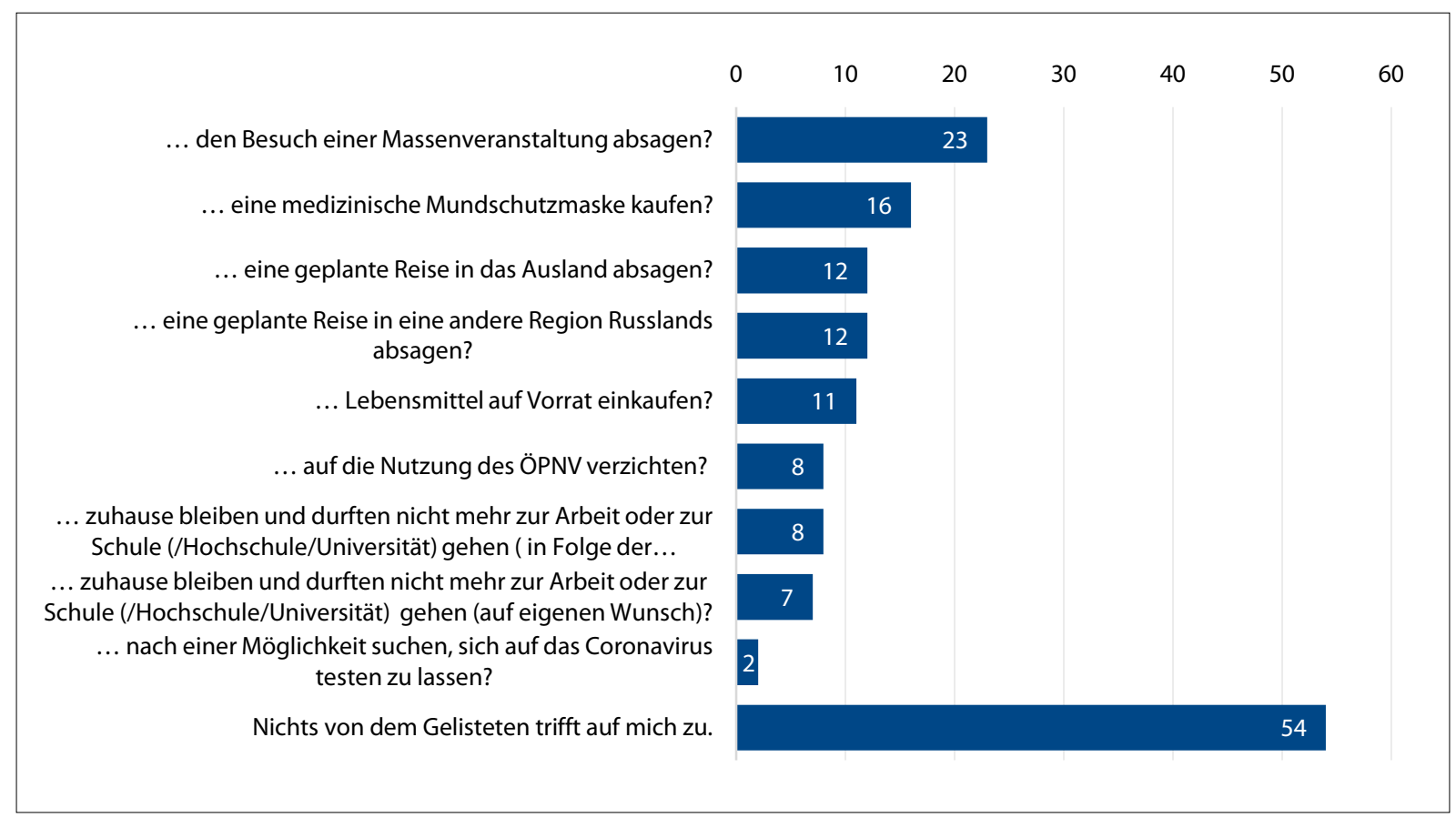

Quelle:repräsentative Umfrage des Lewada-Zentrums vom 19. -25. März2020, www.levada.ru/2020/03/26/pandemiya-koronavirusa/, veröffentlichtam 26.03.2020

Grafik 4: Haben Sie in der letzten Zeit einen Mangel an den folgenden Waren im Verkauf feststellen müssen? (eine Antwort pro Kategorie möglich) (19.-25. März 2020)

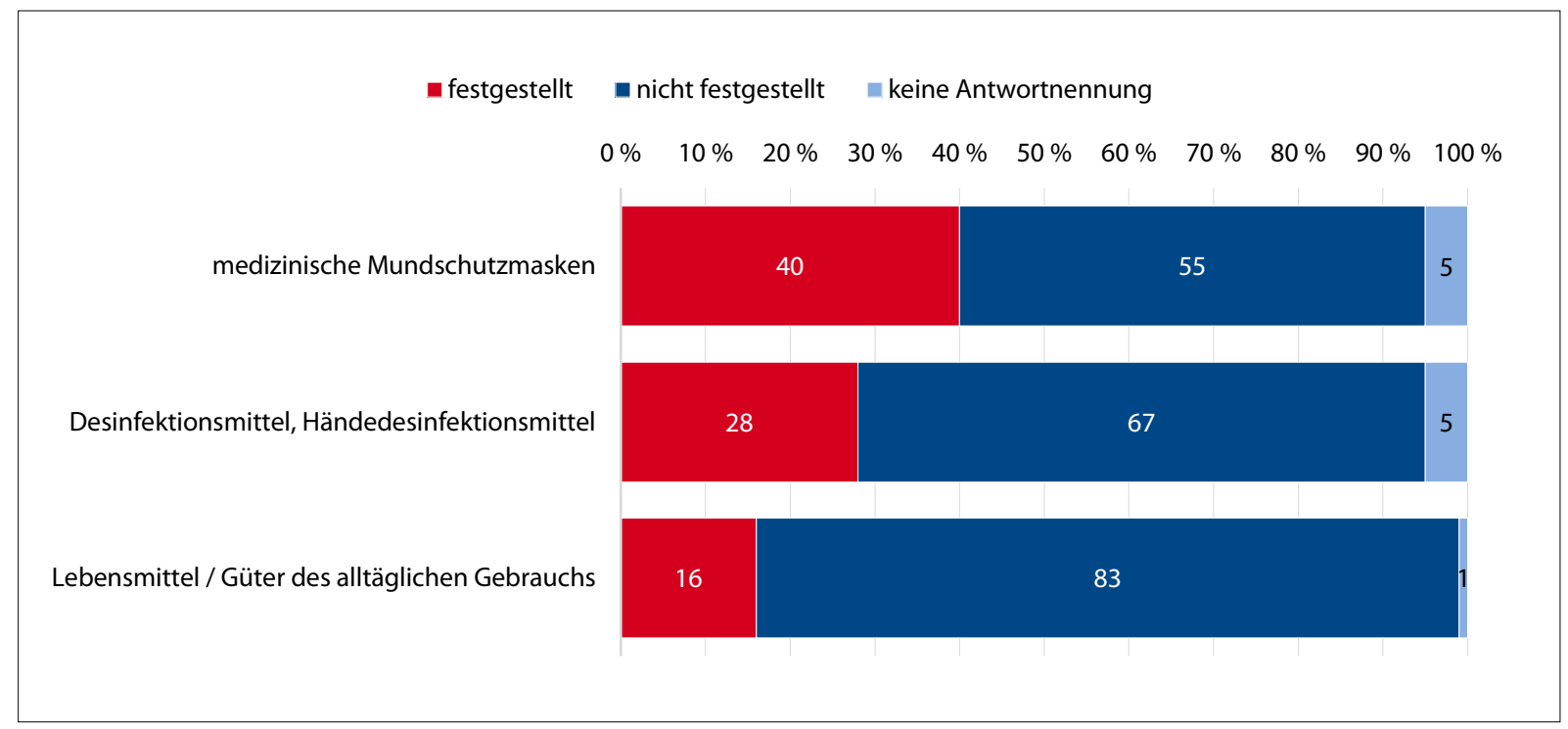

Quelle: repräsentative Umfrage des Lewada-Zentrums vom 19. - 25. März2020, www.levada.ru/2020/03/26/pandemiya-koronavirusa/, veröffentlicht am 26.03.2020 
Grafik 5: Vertrauen Sie der offiziellen Information zur Situation des Coronavirus in Russland, die über die Medien verbreitet wird? (eine Antwortnennung möglich) (19.-25. März 2020)

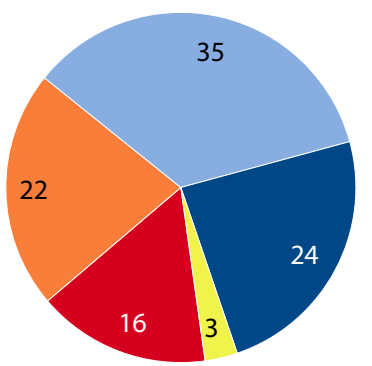

- in vollem Umfang

- in beträchtlichem Umfang

n ich vertraue den Medien zum Teil

— ich vertraue den Medien überhaupt nicht

keine Antwortnennung

Quelle:repräsentative Umfrage des Lewada-Zentrums vom 19. - 25. März2020, www.levada.ru/2020/03/26/pandemiya-koronavirusa/, veröffentlichtam 26.03.2020

Grafik 6: Was glauben Sie, wie wahrscheinlich ist es, dass es in Russland zu einer Coronavirus-Epidemie kommt? (19.-25. März 2020)

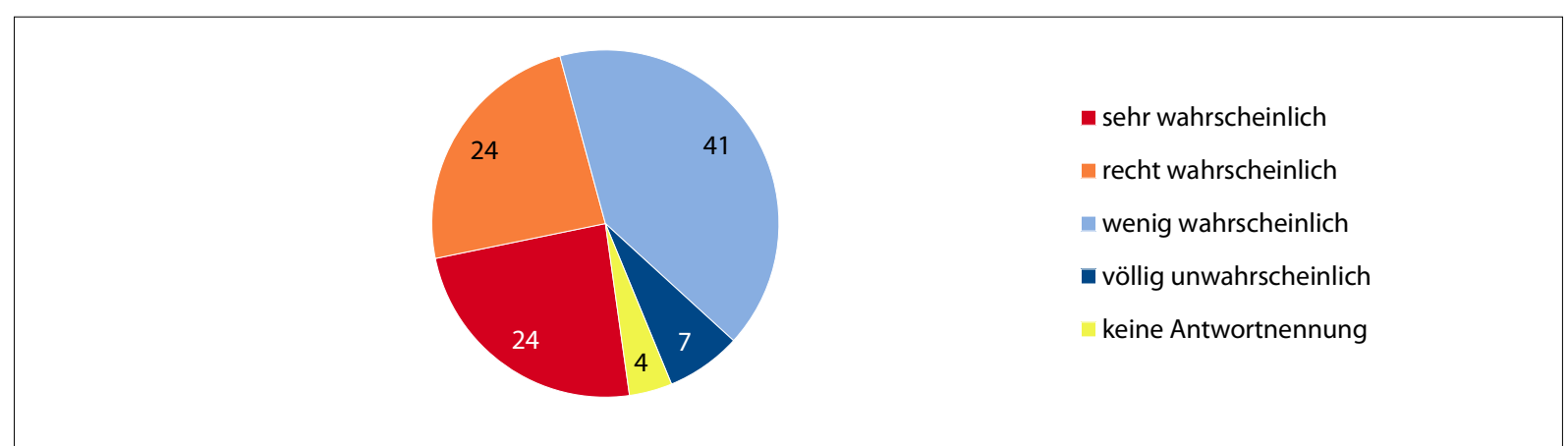

Quelle: repräsentative Umfrage des Lewada-Zentrums vom 19. - 25. März 2020, www.levada.ru/2020/03/26/pandemiya-koronavirusa/, veröffentlicht am 26.03.2020

Grafik 7: Was glauben Sie, wenn es in Russland zu einer Coronavirus-Epidemie kommt, ist dann unser Gesundheitswesen dazu bereit? (eine Antwortnennung möglich) (19.-25. März 2020)

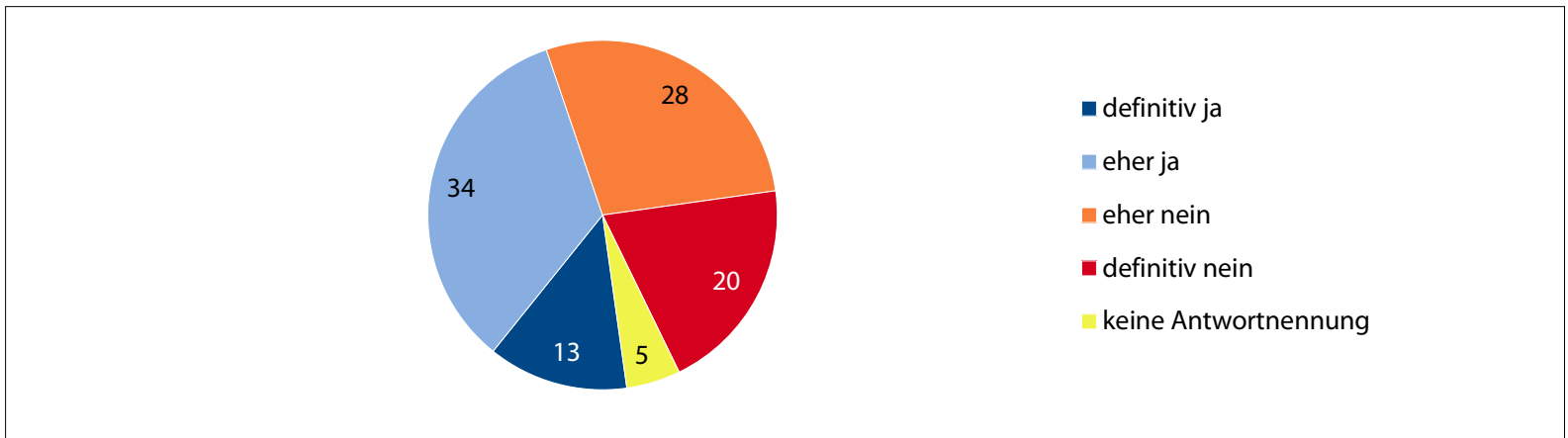

Quelle: repräsentative Umfrage des Lewada-Zentrums vom 19. - 25. März 2020, www.levada.ru/2020/03/26/pandemiya-koronavirusa/, veröffentlicht am 26.03.2020 


\title{
Das Corona-Virus im Vorlauf
}

\author{
Sergej Medwedew (Moskau)
}

Der folgende Beitrag des russischen Politikwissenschaftlers Sergej Medwedew erschien ursprünglich am 15.03.2020 auf seiner privaten facebook-Seite und wurde von dekoder ins Deutsche übersetzt und veröffentlicht.

\section{Einleitung}

Trotz Corona läuft in Russland immer noch vieles nach dem Prinzip Business as usual: Einzelne Stimmen kritisieren in Sozialen Netzwerken, dass die Regierung zwar über ein Maßnahmenpaket zur Stützung der russischen Wirtschaft nachdenkt, bei durchgreifenden Maßnahmen zum Schutz der öffentlichen Gesundheit aber zaghaft bleibt. Sie glauben, dass die seit vergangenem Freitag verhängten Einreisesperren für Menschen aus Westeuropa die Pandemie nicht eindämmen werden und fordern drastischere Schritte: unter anderem die Vertagung der Volksabstimmung am 22. April und die Absage öffentlicher Siegesfeiern am 9. Mai.

Währenddessen empfiehlt das russische Bildungsministerium, selbst zu entscheiden, ob man in die Schule oder Uni geht oder zu Hause bleibt. All dies ist für den russischen Politikwissenschaftler Sergej Medwedew Anlass für einen Kommentar auf Facebook, den 2000 Menschen geteilt haben.

\section{Corona: "Die Rettung ist Sache der Ertrinkenden"}

Die feige "Empfehlung« von Sobjanin und dem Bildungsministerium, dass Schulen und Hochschulen »freiwillig « besucht werden, statt sie komplett zu schließen, ist ein sehr schlechtes Zeichen. Es bedeutet, dass die Behörden mehr Angst vor Panik haben als vor dem Virus selbst - und dass sie eine feige unentschiedene Strategie gewählt haben, um sich der Verantwortung zu entziehen. "Die Eltern spielen in diesem Fall eine größere Rolle«, sagt Sobjanin in seinem Dekret. Also, Stopp mal. Das heißt, nicht die Ärzte, nicht der Epidemie-Stab, sondern die Eltern dürfen entscheiden, ob ihre Kinder potentielle Träger des Virus werden. Das ist nicht nur absurd, das ist kriminell. Man kann nicht ein bisschen schwanger sein, und man kann keine partielle, optionale Quarantäne einführen - entweder Quarantäne oder keine Quarantäne. Schon eine Person, die ausschert, bringt das ganze System zum Einsturz.

Die Behörden scheinen hin und herzuschwanken zwischen der immer dringlicheren Notwendigkeit einer Quarantäne (da die Lawine ausländischer Nachrichten nicht mehr zu verbergen ist) und der Unmöglichkeit, solche Maßnahmen zu ergreifen.

Die Unmöglichkeit ist meines Erachtens rein technischer Natur - wir haben einfach nicht das Niveau an staatlicher und gesellschaftlicher Organisation, an Screenings, Tests, Ausrüstung, Disziplin und strikter Durchsetzung von Gesetzen, wie wir es in China und zum Teil auch in Italien gesehen haben.

\section{Der 9. Mai im postapokalyptischen Bühnenbild à la Wuhan?!}

Wie stellen Sie sich den Shutdown der Moskauer Metro vor? Das wäre eine Katastrophe, keine städtische, son- dern eine nationale. Das Anhalten der 20-MillionenMetropole käme einem Herzstillstand des Landes gleich. Außerdem ist es aus rein politischen Gründen nicht möglich, vor dem 22. April und dem 9. Mai den Notstand auszurufen - das alles sollte in der herrlichen Atmosphäre eines Nationalfeiertags stattfinden, nicht in einem postapokalyptischen Bühnenbild à la Wuhan, in Schutzanzügen, unter einer Chlorhexidin-Dusche.

Daher wird es keine Quarantäne geben, stattdessen feige, halbherzige Maßnahmen wie den freiwilligen Schulbesuch, die »Empfehlungen«, öffentliche Veranstaltungen zu reduzieren (übrigens wenn eine Kundgebung verboten wird, wird das nicht empfohlen, sondern verboten, da gibt es keine Zwischentöne), einen teilweise eingeschränkten Flugverkehr (man nehme nur dieses anekdotische Flugverbot nach Europa, ausgenommen sind die Flüge ins süße Herz der Oligarchen und Abgeordneten nach Großbritannien - da sind doch Kinder, Familien, Häuser!) und so weiter.

Die Mächtigen waschen sich die Hände in Unschuld (entschuldigen Sie den Schenkelklopfer) und sagen der Bevölkerung: Die Rettung der Ertrinkenden ist Sache der Ertrinkenden - entscheiden Sie selbst, wie Sie sich schützen wollen! Sollte was sein - wir haben Ihnen eine Empfehlung gegeben und damit sind wir raus.

\footnotetext{
"Die Rettung der Ertrinkenden ist Sache der Ertrinkenden"

Stattdessen kauft die Bevölkerung brav die Mär von "viralen Atemwegserkrankungen« ab, postet Sprüche, dass jedes Jahr mehr Menschen an Mückenstichen sterben als jetzt an Corona, schimpft auf Panikmacher und Hysteriker und lebt weiter in vollem Genuss und Saus und Braus. Das ist die typische, infantile Reaktion einer unfreien, patriarchalischen, geschlossenen Gesellschaft:
} 
Bedrohung wird verleugnet, Angst verdrängt und man verhält sich ostentativ nachlässig.

Währenddessen ist das Virus hier schon längst angekommen, und nur wenige glauben den lächerlichen Zahlen von 59 erkrankten Menschen [Stand: 15. März 2020] in einem Land mit 146 Millionen Einwohnern, das in alle Richtungen offen ist: Die Chinesen sind ungehindert über den Amur eingereist, ehe im Fernen Osten die Quarantäne verhängt wurde. Und was den europäischen Teil Russlands angeht: Zehntausende sind im Februar und März in die am stärksten verseuchten Regionen Europas gereist und wieder nach Russland zurückgekehrt.

Und je länger es geht, desto lächerlicher werden die offiziellen Zahlen sein, die realen Zahlen werden aber in der allgemeinen Sterbestatistik alter Menschen verborgen sein, unter den saisonalen viralen Atemwegserkrankungen und ambulant erworbenen Lungenentzündungen. In den Sterbeurkunden wird wie immer »akute Herzinsuffizienz« stehen, wie auch beim Tod durch Folter geschrieben wird. Und das alles bestreite mal einer im Nachhinein - eine Insuffizienz hat ja schlussendlich wirklich eingesetzt, alles saubere Fakten.

\section{Erinnerung an den schrecklichen Sommer 2010}

ich erinnere mich an den schrecklichen Sommer 2010, Hitze überall, die Wälder brannten, und Moskau war vom glühenden Smog umhüllt. Damals starben laut inoffiziellen Schätzungen bis zu 40.000 ältere Menschen. Unter ihnen war auch mein 83-jähriger Vater, und als der Polizist schweißgebadet ein Protokoll zur Feststellung der Todesursache verfasste und dann seine Stimme senkte, erzählte er mir, dass allein ihre Abteilung jeden Tag hunderte Todesfälle aufnimmt, in der ganzen Stadt seien es Zehntausende. Dessen ungeachtet gab es jedoch keine Statistik über die hitzebedingte Sterblichkeit, alles löste sich in den üblichen Diagnosen auf, die älteren Menschen gestellt werden.

\section{Wir sind das freieste Land der Welt!}

Deshalb befürchte ich, dass wir im Modus des freien Schulbesuchs, der freien Quarantäne und des freien Sterbens verbleiben werden. Dabei wird der Mensch sogar frei sein von einer Diagnose - wir sind das freieste Land der Welt! Die Politik hat sich aus der Verantwortung gestohlen und mächtige Nebelkerzen gezündet, die das wahre Ausmaß der Epidemie verbergen. Hinzu kommt noch die normale Nachlässigkeit der Bevölkerung, und dann ist der Punkt erreicht, an dem unsere Atomisierung, unser geringes Sozialkapital, das Fehlen von Vertrauen, Disziplin und sozialer Solidarität und das Lagerprinzip »Stirb du heute und ich sterbe morgen« zu uns zurückkommen wird wie ein Bumerang.

\section{Amtszeiten, Verfassungen, Leben - alles wird annulliert}

Ja, die Epidemie wird bis zum Sommer ihre natürliche Grenze erreichen, und Merkel hat wohl Recht, dass 60 bis 70 Prozent der Bevölkerung sich anstecken werden, von denen viele nicht einmal ahnen, dass sie krank sind. Doch gleichzeitig werden nicht nur die Verfassung und Putins Amtszeiten annulliert, sondern auch viele Leben, die man hätte retten können, wenn das oben Beschriebene nicht wäre. Doch wann und wer hat in dem Land der großen Errungenschaften je Menschenleben gezählt?

\section{Übersetzung aus dem Russischen durch die} dekoder-Redaktion

\section{Über den Autor}

Sergej Medwedew (geb. 1966) ist ein russischer Politikwissenschaftler und Historiker. Er ist Professor an der renommierten Moskauer Higher School of Economics, zu seinen Forschungsschwerpunkten gehört vor allem die russische Zeitgeschichte. Medwedew schreibt regelmäßig Artikel für unabhängige Medien, in den liberal-demokratischen Kreisen gilt seine Stimme als sehr gewichtig.

Das russischsprachige Original des vorliegenden Beitrags ist online verfügbar unter https://www.facebook.com/sergei. medvedev3/posts/10222057345250983, die Übersetzung ins Deutsche durch dekoder unter https:/www.dekoder.org/ de/article/corona-quarantaene-massnahmen-sobjanin.

Dieser Beitrag wurde übernommen im Rahmen des Projektes "Wissenstransfer ${ }^{2}$ - Russlandstudien«, das von der Forschungsstelle Osteuropa an der Universität Bremen und dekoder.org mit finanzieller Unterstützung der VolkswagenStiftung durchgeführt wird.

Die Redaktion der Russland-Analysen freut sich, dekoder.org als langfristigen Partner gewonnen zu haben. Auf diesem Wege möchten wir helfen, die Zukunft eines wichtigen Projektes zu sichern und dem russischen Qualitätsjournalismus eine breitere Leserschaft zu ermöglichen. Wir danken unserem Partner dekoder und Sergej Medwedew für die Erlaubnis zum Nachdruck.

Die Redaktion der Russland-Analysen 


\section{Die Seuche, Igor Setschin und Allahs Wille}

Wladislaw Inosemzew, Irina Tumakowa (Novaya Gazeta)

Das folgende Interview mit dem russischen Wirtschaftswissenschaftler Wladislaw Inosemzew erschien ursprünglich am 18.03.2020 in der Zeitung Novaya Gazeta und wurde von dekoder in einer gekürzten Fassung ins Deutsche übersetzt und veröffentlicht.

\section{Einleitung}

Anfang März haben sich die 13 Staaten des Ölkartells OPEC mit Russland und anderen Erdöl exportierenden Ländern in Wien an einen Tisch gesetzt. Um der weltweit sinkenden Nachfrage nach Öl- und Ölprodukten zu begegnen, wollten sie gemeinsam die Fördermenge drosseln und damit das Angebot verknappen. Das Vorhaben scheiterte: Vor allem der russische Unterhändler Alexander Nowak hatte sich gegen eine Verknappung gestemmt.

Seitdem sprudeln weltweit die Ölquellen, und die Preise purzeln: Ein Barrel Brent ist derzeit für unter 30 US-Dollar zu haben, die für Russland wichtigste Rohölsorte Urals kostet ohne Rabatte weniger als 25 USDollar - bei Förderkosten, die manche ausländischen Experten auf rund 42 US-Dollar taxieren.

Dumping würden aber vor allem »die anderen« betreiben, sagte kürzlich Rosneft-Chef Igor Setschin, und verwies vor allem auf Saudi-A rabien. Dabei betragen die Förderkosten für saudisches Öl laut derselben Schätzung rund 17 US-Dollar. Aus diesem Grund kann sich das Land offenbar auch leisten, derzeit großzügige Rabatte auf den Marktpreis zu gewähren - auch für Abnehmer in Europa und China, die traditionell Russlands Kunden sind. Die Folge ist ein Preiskrieg, bei dem Russland zunehmend vom Markt verdrängt wird.

War dieser Preiskrieg gewollt, als Russland in Wien ausscherte? Haben sich Setschin und Nowak dabei verkalkuliert? War ihnen nicht klar, dass der Rubelkurs eng am Ölpreis hängt? Und was wird das Coronavirus mit der Weltwirtschaft im Allgemeinen und mit dem russischen Rubel im Besonderen machen? Die Novaya Gazeta hat den Wirtschaftswissenschaftler Wladislaw Inosemzew in einem Interview dazu befragt.

Irina Tumakowa: Wovon steckt mehr in den beispiellosen Sicherheitsmaßnahmen in verschiedenen Ländern wegen des Coronavirus - Epidemiologie, Psychologie oder Politik? Ich kann mich an keine derartigen Dimensionen erinnern, etwa während der Schweinegrippe. Obwohl es in den USA damals auch eine strenge Quarantäne gab.

Wladislaw Inosemzew: Politik und Wirtschaft stecken keineswegs dahinter, aus Sicht der Politik und der Wirtschaft ist das alles einfach nur kontraproduktiv. Das wichtigste ist hier, dass die Verluste durch die Epidemie und die Verluste durch die Reaktion auf die Epidemie nicht zu vergleichen sind. Letztere sind tausendmal größer.

Ich verstehe, dass das sehr zynisch klingt und den Lesern nicht gefallen könnte, aber auch Menschenleben haben einen Preis. In Russland werden den Angehörigen der Opfer von Terroranschlägen und Katastrophen einige Millionen Rubel gezahlt. Das ist natürlich lächerlich. In den meisten entwickelten Ländern, besonders in den USA, in denen die Praxis der Entschädigungen schon seit langem ausgefeilt ist, erreichen die Zahlungen bei Todesfällen in der Produktion, bei einem Terroranschlag usw. im Schnitt 8 - 10 Millionen Dollar. Wenn wir uns die Dimension der Schäden anschauen, die durch 6.000 Todesfälle entstehen, dann erkennen wir, dass der Schaden durch die Panik und die beschlossenen Maßnahmen sich eben nicht auf 60 Milliarden Dollar beläuft. Das sind schon etliche Trillionen. Und diese Unverhältnismäßigkeit wirft Fragen auf.

IT: Ja, aber die Maßnahmen werden ja unternommen, damit die Zahl der Todesfälle nicht mehr ansteigt.

WI: Möglich, aber wegen der Maßnahmen verschlechtert sich die Situation in der Wirtschaft nur noch weiter. Anfang Februar hatten wir nur China, wo es wegen der Quarantäne bergab ging. Jetzt ist das gleiche weltweit zu beobachten: Tausende Veranstaltungen werden abgesagt, Verluste der Fluggesellschaften, Katastrophen auf den Märkten, Preisverfall der Wertpapiere. Der Schaden durch die Reaktionen übersteigt den Schaden durch die eigentliche Epidemie.

IT: Könnte man denn etwa die Epidemie eindämmen, ohne die Wirtschaft derart zu schädigen? 
WI: Man hätte meiner Meinung nach, eine einfache Sache tun können: bestimmte Entschädigungen anbieten, Vergütungen an jene zahlen, die sich testen lassen, und sie [bei Bedarf] in Krankenhäuser einliefern. Alle anderen Leute leben ihr gewohntes Leben weiter und beachten alle Vorsichtsmaßnahmen; der Kampf gegen andere Krankheiten sollte auch nicht vergessen werden. Es scheint aber, dass wir jetzt sehen, warum das nicht gemacht wird: In praktisch allen Ländern außer vielleicht in Südkorea, fehlt die nötige Menge Tests, um die Krankheit festzustellen.

Technisch und finanziell sind die Regierungen nicht auf eine Antwort vorbereitet und verhalten sich auch genau so, wobei sie einen noch größeren Schaden anrichten.

\section{IT: Warum so streng?}

WI: In China, nehme ich an, hat innerhalb der herrschenden Hierarchie Angst geherrscht. In einzelnen Provinzen wurden Städte dicht gemacht, weil man befürchtete: Wenn das alles in dieser Dimension bis nach Peking kommt, dann gibt es katastrophale politische Folgen. Dieser Prozess wirkte dann wie eine Lawine. Wenn wir von Europa und den Vereinigten Staaten sprechen, so scheint mir, dass die Politiker verstehen, was sie sagen können: Es können ruhig einige Hundert Menschen sterben, Hauptsache, die Wirtschaft bricht nicht zusammen. Das sorgt auch für den Wunsch, Besorgtheit zu demonstrieren. Doch die sieht auch nicht überzeugend aus. Da haben sie im Bundesstaat New York, und dann in den USA den Ausnahmezustand eingeführt. Und wer hat was bemerkt? Wurde die U-Bahn geschlossen? Wenn Sie sich die Internetseiten der lokalen Verkehrsunternehmen anschauen, dann stellen Sie fest, dass das nicht der Fall ist. Es gehen keine Flüge mehr nach Europa? Schauen Sie bei flightradar24 nach.

\section{IT: Ist denn die Angst von Politikern vor der öffentlichen Meinung keine Politik?}

WI: Das ist nicht Politik, das ist irgendein Populismus. Wenn wir im 19. Jahrhundert leben würden, wäre das normal. Dann könnten Sie beim Studium einige Monate Pause machen, und weiter? Nun, dann schließen Sie für eine Zeit lang Cafés und Restaurants... Das heißt, es gibt gewisse Folgen für die Wirtschaft, aber keine katastrophalen. Selbst wenn die Fluglinien ihre Flüge für zwei Monate um ein Drittel reduzieren, ist das keine Branche, die eine Rezession in Gang setzen würde. Die Panik heute hat jedoch riesige Folgen durch den Absturz der Wertpapiermärkte. Die Bestände der Rentenfonds gehen zurück. Das beeinträchtigt die Bereitschaft der Menschen, Geld auszugeben.

Nach den Hamsterkäufen von Nudeln, Konserven und Klopapier werden sich die Verkäufe in den Handelsketten nur langsam normalisieren. Die Produktion wird zurückgehen.

Das Wirtschaftssystem ist heute zu komplex, als dass solche Regulierungsmaßnahmen nicht schwerwiegende Folgen haben würden. Wäre sie einfacher strukturiert, nun, sagen wir mal, wie die sowjetische, dann wären das Kleinigkeiten: Dann würden fünf Städte unter Quarantäne stehen, alles kein Beinbruch. Das Problem ist eben, dass wir jetzt den Herausforderungen des 21. Jahrhundert mit Methoden des 19. Jahrhunderts zu begegnen versuchen.

IT: Warum gibt es durch die Reaktion auf die Krankheit derartige wirtschaftliche Folgen? Was ist hier der Mechanismus?

WI: Nun, stellen Sie sich mal vor: Das BIP der USA besteht zu 82 Prozent aus dem Mehrwert im Dienstleistungsbereich. Und Sie schließen die Universitäten und halten keine Meetings mehr ab. Die Weltbank beispielsweise hat ihre Jahressitzung abgesagt. Das bedeutet, dass 2 - 3.000 Menschen, die in den Hotels die teuersten Zimmer buchen, nicht nach Washington kommen. Die Fluggesellschaften befördern nicht diese Menge Menschen. Die Restaurants verlieren Kunden. Und so weiter. Aber wenn, wie in den letzten Tagen, die Beschränkungen mit Zwang und umfassend eingeführt werden, wird es nur schlimmer.

IT: Wie langwierig könnten die Folgen sein? Das Leben geht weiter, die Epidemie hört auf, nach dem Rückgang der Nachfrage müsste ein Boom einsetzen, der das dann in einem gewissen Maße kompensiert.

WI: Ich bin überzeugt, dass sich die Wirtschaft recht schnell erholen wird, und auch die Wertpapiermärkte. Und das lässt mich umso mehr daran zweifeln, dass die derzeitigen Maßnahmen angemessen sind. Zur einzigen Ausnahme könnten wohl die inerten und regulierten Märkte werden, eben der Ölmarkt zum Beispiel.

\section{IT: Warum?}


WI: Der funktioniert zeitverschoben, um eine Spanne von 2 - 3 Monaten. Im Dezember werden die Futures für März gehandelt. Also, ein chinesisches Unternehmen kauft eine Partie Öl. Im Januar beginnt die Epidemie, im Februar sinkt die Nachfrage, aber die Tanker aus Saudi-Arabien sind in Shanghai angekommen und werden entladen. Alle möglichen Öllager in China sind randvoll. Im April beginnt der Markt sich wieder zu beleben. Wie viele Monate wird China kein Öl einkaufen müssen? Noch zwei Monate. Dann ist schon Juni, Juli, und die Nachfrage nach Öl liegt dennoch rund 10 Prozent unter dem üblichen Niveau. Und wenn die Ölpreise ein halbes Jahr lang im Bereich von 35 Dollar pro Barrel liegen, dann ändert sich die Haltung zur Möglichkeit, dass die Wirtschaft wieder nach oben schnellt, sehr stark.

IT: Das hat Russland und andere ölfördernde Länder getroffen. Es gibt aber sehr viel mehr Länder, die Öl kaufen. Für diese Volkswirtschaften ist doch ein Rückgang der Ölpreise gut, oder? Benzin zum Beispiel wird billiger.

WI: Das Benzin wird bei ihnen wohl kaum viel billiger werden. In Europa und in Russland ist die Preisbildung hier ähnlich: Rund 80 Prozent sind Steuern. Ich nenne nur eine Ziffer: Wenn die Benzinpreise in den USA um 40 Prozent zurückgehen, braucht es 15 Jahre, damit die Haushalte so viel einsparen, wie die Investoren am 9. März 2020, an nur einem Tag verloren haben. Noch Fragen? Die Epidemie hätte natürlich sehr wohl zur rechten Zeit und nützlich sein können, wenn die Panik nicht solche Ausmaße angenommen hätte...

\section{IT: Nützlich? Wie das?}

WI: Die Wirtschaft entwickelt sich schon seit langem aufgrund gigantischer Kreditspritzen. Zur Stützung des Wachstums sind mehrfach die Steuern gesenkt worden. Natürlich nicht in Russland. Und dieser Wirtschaftszyklus hat sich extrem in die Länge gezogen: Der Aufschwung setzt sich anderthalb Mal länger fort, als im Schnitt der letzten 50 Jahre. Alle erwarteten eine Krise, eine zyklische, anhaltende, lange.... Wenn das Coronavirus ein kurzer Moment der Ernüchterung gewesen wäre, dann hätte das die Rettung sein können: Die überbewerteten Aktiva würden billiger, das Produktionsvolumen würde für eine Zeit zurückgehen, dann würde es eine Erholung geben. Eine zufällige kurze Krise würde von den Märkten als zyklischer Rückgang wahrgenommen. Die Staaten würden Geld zuschießen. Dann hätten wir keine Rezession, die vor unserer Nase tanzt. Das wäre alles sehr positiv gewesen.

Wenn sich plötzlich nach zwei Wochen herausstellen sollte, dass die Epidemie zurückgeht, wird ein solches Szenario schon nicht mehr Wirklichkeit werden können. Das Jahr wird mit einer geringen Rezession oder mit einem Nullwachstum zu Ende gehen, danach wird sich wieder Wachstum einstellen, weil die Menschen die aufgeschobene Nachfrage nachholen. Der Flugverkehr wird wieder aufgenommen, alles wird wieder normal. Wenn das passiert, dann wird es super. Die Wirtschaft wird weiter wachsen, obwohl die Rezession wohl unausweichlich war.

\section{IT: Der Anstieg der Erkranktenzahlen in Europa deutet aber darauf hin, dass es wohl lange dauern wird.}

WI: Das denke ich auch. Und wenn dem so ist, dann rutscht die Weltwirtschaft ins Minus, dann wird sich eine Rezession auf die nächste legen, und es könnte sich eine recht traurige Situation ergeben.

\section{IT: Inwieweit ist das Coronavirus schuld daran, dass der Rubelkurs derart gefallen ist? Und inwieweit hat es andere Gründe?}

WI: Das Coronavirus ist gewissermaßen ein Trigger. In letzter Zeit sind die Ölpreise weltweit zurückgegangen. Weil die Nachfrage sehr langsam stieg und zu spüren war, dass sie sich weiter verlangsamt. Die OPEC hat im November 2019 einen Bericht veröffentlicht, in dem sie prognostiziert, dass die Wachstumsraten bei der Ölnachfrage in den kommenden 20 Jahren bei einem Drittel dessen liegen werden, was wir aus den vergangenen 20 Jahren kennen. Die Abmachung der OPEC von 2016 sollte die Ölpreise ansteigen lassen. Es hat aber keinen Anstieg gegeben. Im Gegenteil: Sie gingen mit jedem Jahr zurück. Als dann das Coronavirus kam, war die erste Welle des Preisverfalls eine absolut natürliche Reaktion auf die Epidemie und die Maßnahmen der Regierungen in den verschiedenen Ländern. Wenn die OPEC-Abmachung bis zum April gehalten hätte, wären Preise von 45 bis 50 Dollar, wie wir sie noch bis Anfang März hatten, weiterhin möglich gewesen.

IT: Genau das wollten die OPEC-Länder bei ihrem Treffen Anfang Dezember 2019 in Wien auch erreichen, so wie ich das verstehe. 
WI: Saudi-Arabien und andere Länder wollten die Produktion noch weiter drosseln, aber Russland war nicht bereit dazu, und die Abmachung platzte. Die letzten Preisrückgänge waren unmittelbar darauf zurückzuführen, dass Saudi-Arabien seinen Kunden riesige Preisnachlässe versprochen und erklärt hatte, dass es bereit sei, um einzelne Märkte einen Krieg zu beginnen - insbesondere um den europäischen Markt, und dazu das Förder- und Absatzvolumen zu erhöhen.

\section{IT: Das heißt, die staatlichen Fernsehsender haben Recht? Ist Saudi-Arabien tatsächlich an allem Schuld, nicht wir?}

WI: Russland hat das Abkommen abgelehnt und seine primäre Verantwortung für den Rückgang der Ölpreise liegt auf der Hand. Doch schauen wir uns einmal die Preis-Charts von Freitag, dem 6. März an, und die Erklärung aus Wien, dass das Abkommen geplatzt ist: Von einem Scheitern des Abkommens war bereits am 4. März die Rede, als Nowak nach Moskau abgereist war. Der Ölpreis fiel um fünf bis sechs Prozent. Am Freitag, 6. März, nachdem er zurückgekehrt war und wieder keine Einigung zustande kam, fiel der Ölpreis um weitere vier Prozent und stabilisierte sich bei rund 44 Dollar pro Barrel. Weiter dann, am Wochenende, erklärten die Saudis, dass sie den Europäern und Amerikanern einen Rabatt von 7 bis 8 Dollar auf den aktuellen Preis geben. Sie haben also gesagt: Wir werden nicht für 45, sondern für 37 Dollar verkaufen.

Riad war wegen der Position Moskaus empört. Und Mohammed bin Salman ist eben nicht irgendein Schröder, der davon träumt, an die Tränke von Rosneft zu gelangen.

Gegenüber dem berüchtigten Charisma von Putin herrscht hier Immunität. So war also letztendlich das Handeln Saudi-Arabiens der Grund, dass die Ölpreise derart stark nachließen. Übrigens nicht aus Versehen, sondern vollkommen bewusst.

IT: Eine solche Reaktion Saudi-Arabiens hätte man wohl voraussehen können. War der Nutzen durch den Ausstieg aus dem OPEC-Abkommen für Russland größer als der Schaden durch mögliche Folgen? Inwieweit ist dieser Abzug im Interesse Russlands?

WI: Er ist überhaupt nicht im Interesse Russlands. Man hätte ihn aber voraussehen können.

IT: Der Chef von Rosneft verkündet, die Förderung anzukurbeln und die Produzenten von Schieferöl in den Ruin zu treiben. Experten haben aber vielfach gesagt, dass Russland die Förderung bei niedrigen Preisen nicht wird steigern können; die meisten Vorkommen sind nur schwer zu fördern, verbunden mit hohen Kosten. Wo liegt da für Rosneft der Sinn?

WI: Das müssten Sie Setschin fragen; ich stimme Ihnen da vollkommen zu. Das Problem ist auch, dass man die USamerikanischen Schieferölproduzenten nicht kaputtmachen kann.

\section{IT: Das haben die Amerikaner schon mehrfach bewiesen.}

WI: Ja, das haben sie, das ist das eine. Und es gibt noch einen zweiten Aspekt: Vor einigen Tagen hat die Bank of England den Schlüsselzinssatz gesenkt, vergangene Woche auch die Fed. Selbst wenn eine amerikanische Ölfirma auf Null arbeiten muss, würde es sie nichts kosten, Überbrückungskredite aufzunehmen - und mit dem Ausblick auf steigende Preise weiterzumachen. Selbst wenn irgendeine verrückte Bank versuchen würde, die Firma in den Ruin zu treiben, kann man Insolvenz beantragen und viele Jahre unter dem Schutz des berühmten Chapter 11 des US-amerikanischen Insolvenzrechts tätig sein, während die Umstrukturierung läuft. Dieser Zeitraum kann sich zwei bis drei Jahre hinziehen. In dieser Zeit würde Russland schlichtweg pleitegehen. Und die amerikanischen Firmen würden weiter Öl pumpen, weil sie zumindest für die Löhne und zur Kostendeckung Einnahmen brauchen.

IT: Und für Rosneft gibt es keine Möglichkeit für Überbrückungskredite zu niedrigen Zinssätzen, es fällt ja unter die Sanktionen, in Europa und den USA wird man keine Kredite geben.

WI: Russland hat viele Reserven, mit denen Ölfirmen unterstützt werden können. Anstelle von Krediten wären da Steuererleichterungen, der Fonds für nationale Wohlfahrt [FNB], auf den Setschin seit langem schimpft, und so weiter. Ich meine einfach, dass die ganze Logik, mit der Rosneft die amerikanischen Unternehmen kaputt machen will, sehr lächerlich wirkt. 


\section{IT: War das denn wirklich die Logik dahinter? Vielleicht hat Herr Setschin ja auch ganz andere Motive?}

WI: Na, ich weiß nicht. Vielleicht will er die Preise ruinieren, damit sich der Börsenwert von Lukoil halbiert, und er dann mit Hilfe eines Strafverfahrens gegen Alekperow das Unternehmen kaufen kann. Wie das mit Baschneft der Fall war. Warum auch nicht? Wir wissen nicht, was Setschin im Sinn hat. Wie dem auch sei, auf der Sitzung bei Putin war niemand außer Setschin dafür, den Deal platzen zu lassen.

IT: Also steht der Staat vor der Alternative: Entweder er unterstützt Rosneft, das gegen die Amerikaner Krieg führt, oder der Staat erfüllt seine sozialen Verpflichtungen gegenüber der Bevölkerung?

WI: Das würde ich so nicht sagen. Der Staat verfügt wirklich über sehr große Reserven. Der Haushalt des vergangenen Jahres ist nicht vollkommen ausgeschöpft worden. Der FNB beläuft sich jetzt auf 124 Milliarden Dollar. Unter Berücksichtigung der Abwertung sind das rund zehn Prozent des BIP. Der Staatshaushalt macht etwa 18 Prozent des BIP aus. Selbst wenn dort eine Lücke von drei Prozent entsteht, dann können bei den heutigen Reserven alle festgeschriebenen sozialen Verpflichtungen zwei, drei, ja sogar vier Jahre lang ohne große Probleme erfüllt werden. Außerdem ist der Haushalt nicht die ganze Wirtschaft, es gibt noch den privaten Sektor. Der Dollar steigt, die Einkommen sinken. Die Bevölkerung überlegt, ob man nicht etwas für schlechte Zeiten zurücklegen sollte, schließlich ist es ja beunruhigend. Die Leute gehen nicht mehr in Cafés, fahren nicht mehr in Urlaub und kaufen keine teuren Sachen.

IT: Das haben wir 2015 gesehen, als der Rubel gegenüber dem Dollar einbrach. Übrigens ebenfalls durch das Vorgehen von Rosneft und dessen Chef.

WI: Ja. Außerdem fällt der Rubel - die Zentralbank ist gezwungen, mit einer Erhöhung der Zinssätze zu antworten. Kredite werden teurer, die Käufe von Wohnraum auf Hypothek und Autos auf Kredit gehen zurück. Das heißt, die Realwirtschaft wird sich abschwächen, selbst wenn der Haushalt wie ein Uhrwerk funktioniert. In Russland ist somit ein Wirtschaftsrückgang absolut unausweichlich.

\section{IT: Und das alles nur deshalb, weil allein Igor Iwanowitsch Setschin aus dem Deal mit der OPEC aussteigen wollte?}

WI: Wir haben hier die Effekte sowohl durch das Coronavirus als auch durch Setschin, und dadurch, dass unsere Wirtschaft zu stark reguliert ist, um angemessen auf Herausforderungen zu reagieren.

Doch der Setschin-Effekt ist nicht zu vernachlässigen. Offenbar ist Setschin einer der größten Newsmaker in der russischen Wirtschaft, wir konnten das auch schon früher sehen, auch beim Deal mit Baschneft und in anderen Situationen. Sein Einfluss sollte nicht unterschätzt werden.

\section{IT: Wie geht es weiter mit dem Rubel?}

WI: Ich glaube nicht, dass morgen schon etwas Katastrophales passiert. Ich hatte in diesen Tagen einen sehr viel stärkeren Rückgang erwartet. Ich denke, die Regierung wird den Rubel erst einmal stützen. Für die Menschen in Russland ist der Devisenkurs ein wichtiges symbolisches Moment. Wir erinnern uns an die Situation im Januar 2016, als der Ölpreis innerhalb weniger Tage auf 29 Dollar pro Barrel zurückging und der Dollar auf 85 Rubel hochschnellte. Jetzt gibt es diese Panik nicht. Und das ist gut: Die Zentralbank und das Finanzministerium verfolgen eine sehr viel angemessenere Politik, und die Wirtschaft reagiert nicht so empfindlich auf die Ereignisse. Deswegen schließe ich mich nicht der »100 Rubel für 1 Dollar«-Prognose an. Der neue Korridor wird bei 72 bis 75 Rubeln liegen in den nächsten paar Monaten. Der Kreml wird nicht erklären, wie schön das ist - wie Putin das mal gesagt hat -, wenn man für einen Dollar mehr Rubel kaufen kann. Das Regime spürt jetzt: Seine Popularität ist längst nicht so groß, dass man die Geduld der Bevölkerung auf die Probe stellen könnte.

Ein allzu drastischer Kursrückgang wird nicht begrüßt, doch im Weiteren wird dann alles davon abhängen, was die Saudis machen: Wie stark sie tatsächlich die Ölförderung ankurbeln und in welchem Maße sie den Markt mit ihren Preisnachlässen erobern. Der Rubel ist jetzt von Mohammad bin Salmans Willen abhängig - möge Allah ihn behüten! 


\section{Über den Autor}

Wladislaw Inosemzew $\left({ }^{*} 1968\right)$ ist Wirtschaftswissenschaftler und Publizist. Ausgebildet an der renommierten Moskauer Lomonossow-Universität, war er unter anderem bis 2003 im Vorstand der Moskau-Pariser Bank tätig. Er betätigte sich ab 2010 in der politischen Opposition bei der Partei »Prawoje delo» (dt. »Die Rechte Sache«), ist aber auch Mitglied mehrerer offizieller Beratungsorgane - etwa dem Russischen Rat für Internationale Beziehungen. Inosemzew schreibt regelmäßig für Zeitungen und Internetmagazine, u. a. Vedomosti, Slon, The New Times und RBC.

Das russischsprachige Original des vorliegenden Beitrags ist online verfügbar unter https://novayagazeta.ru/articles/ 2020/03/16/84340-zaraza-sechin-i-volya-allaha, die Übersetzung ins Deutsche durch dekoder unter https://novayagazeta. ru/articles/2020/03/16/84340-zaraza-sechin-i-volya-allaha.

Dieser Beitrag wurde übernommen im Rahmen des Projektes "Wissenstransfer ${ }^{2}$ - Russlandstudien«, das von der Forschungsstelle Osteuropa an der Universität Bremen und dekoder.org mit finanzieller Unterstützung der VolkswagenStiftung durchgeführt wird.

Die Redaktion der Russland-Analysen freut sich, dekoder.org als langfristigen Partner gewonnen zu haben. Auf diesem Wege möchten wir helfen, die Zukunft eines wichtigen Projektes zu sichern und dem russischen Qualitätsjournalismus eine breitere Leserschaft zu ermöglichen. Wir danken unserem Partner dekoder, Novaya Gazeta, Wladislaw Inosemzew und Irina Tumakowe für die Erlaubnis zum Nachdruck.

Die Redaktion der Russland-Analysen

\section{nekóder}

[RUSSLAND ENTSCHLÜSSELN]

\section{CHRONIK}

\section{6. - 29. März 2020}

\begin{tabular}{|l|l|}
\hline 16.03.2020 & $\begin{array}{l}\text { Im Alter von 77 Jahren erliegt der Schriftsteller, Publizist und Politiker Eduard Limonow in Moskau seinem Krebs- } \\
\text { leiden. Limonow war 1974 in die USA emigriert und in den 1990er Jahren nach Russland zurückgekehrt. Er war } \\
\text { bis zu seinem Tod politisch aktiv, zunächst als Gründer der verbotenen Nationalbolschewistischen Partei Russ- } \\
\text { lands und später als Vorsitzender der offiziell nicht registrierten Partei »Drugaja Rossija» (dt. »Anderes Russland«). }\end{array}$ \\
\hline 18.03.2020 & $\begin{array}{l}\text { Unter dem Eindruck weiterhin sinkender Ölpreise gibt der Rubel weiter nach. Ein Euro kostet bei Börsenschluss } \\
\text { 88 Rubel. Dies ist der niedrigste Stand seit Februar 2016, direkt nach Zusammenbruch des Ölmarkts aufgrund } \\
\text { des Scheiterns des OPEC-Vertrags zur Reduzierung der weltweiten Ölförderung. Aufgrund geringerer Nachfrage } \\
\text { und einer Steigerung der Ölfördermenge durch Saudi-Arabien ist der Preis für ein Barrel Öl auf unter 27 US- } \\
\text { Dollar gesunken. }\end{array}$ \\
\hline 21.03.2020 & $\begin{array}{l}\text { Finanzminister Anton Siluanow gibt bekannt, dass das russische Bruttoinlandsprodukt wie prognostiziert seit } \\
\text { Jahresbeginn um 2,3\% gewachsen sei. }\end{array}$ \\
\hline 21.03.2020 & $\begin{array}{l}\text { Der russische Präsident Wladimir Putin verleiht dem russischen Außenminister Sergej Lawrow den Titel »Held } \\
\text { der Arbeit«. Lawrow ist seit 2004 russischer Außenminister; am 21. März 2020 feiert er seinen 70. Geburtstag. } \\
\text { Den Titel »Held der Arbeit« gibt es seit 2013. Durch die Verleihung werden besondere Arbeitsleistungen für den } \\
\text { Staat und das Volk gewürdigt. }\end{array}$ \\
\hline 23.03.2020 & $\begin{array}{l}\text { Der stellvertretende Verteidigungsminister Aleksandr Fomin erklärt, dass das Exportvolumen russischer Militär- } \\
\text { produkte im Jahr 2019 mehr als 15,2 Milliarden US-Dollar betrug. Fomins Angaben zufolge exportierte Russland } \\
\text { militärisches Gerät in fast 50 Länder. Damit sei es einer der Weltmarktführer in diesem Bereich. }\end{array}$ \\
\hline
\end{tabular}




\begin{tabular}{|c|c|}
\hline 23.03 .2020 & $\begin{array}{l}\text { Aleksandr Sharow, Leiter des »Föderalen Dienstes für die Aufsicht im Bereich der Kommunikation, Informa- } \\
\text { tionstechnologie und Massenkommunikation» (kurz: Roskomnadsor), tritt von seinem Posten zurück. Er wird } \\
\text { neuer Generaldirektor von "Gazprom Media», nachdem der frühere Generaldirektor, Dmitrij Tschernyschenko, } \\
\text { im Januar zum stellvertretenden Ministerpräsidenten ernannt worden war. Neuer Leiter von Roskomnadsor wird } \\
\text { voraussichtlich Andrej Lipow, zurzeit Leiter der Abteilung für die Entwicklung von Informations- und Kommu- } \\
\text { nikationstechnologien und Infrastruktur in der Präsidialverwaltung. }\end{array}$ \\
\hline 23.03 .2020 & $\begin{array}{l}\text { Das russische Energieunternehmen "Rosneft" beginnt mit dem Rückkauf von Aktien. Bis Börsenschluss an der } \\
\text { Moskauer und der Londoner Börse seien insgesamt 1,5 Millionen Aktien gekauft worden. Der Vorstand erhofft sich } \\
\text { damit, den Verkehrswert des Unternehmens an den Börsen zu steigern und den Aktionären bei Kursschwankun- } \\
\text { gen höhere Renditen bieten zu können. Das Rückkaufprogramm war bereits im August } 2018 \text { beschlossen worden. }\end{array}$ \\
\hline 24.03 .2020 & $\begin{array}{l}\text { Der russische Internetkonzern »Yandex« beschleunigt sein laufendes Rückkaufprogramm von Aktien. Dieses hatte } \\
\text { der Konzern im November } 2019 \text { angekündigt. Es ist auf zwölf Monate angelegt und sieht einen Rückkauf von } \\
\text { Aktien im Wert von bis zu } 300 \text { Millionen US-Dollar vor. }\end{array}$ \\
\hline 25.03 .2020 & $\begin{array}{l}\text { Nach der Nachricht über den Rückkauf von Aktien durch den Internetkonzern "Yandex« steigt der Preis für Aktien } \\
\text { des Konzerns bei Börsenbeginn um 5,3\%. }\end{array}$ \\
\hline 28.03 .2020 & $\begin{array}{l}\text { Die russische Regierung beteiligt sich zum achten Mal in Folge an der vom »World Wildlife Fund« (WWF) ins } \\
\text { Leben gerufenen "Earth Hour«. Um 20:30 Uhr Ortszeit wird im Moskauer Kreml sowie auf dem Roten Platz in } \\
\text { Moskau die elektrische Außenbeleuchtung für eine Stunde abgeschaltet. Ziel der»Earth Hour» ist es, den Menschen } \\
\text { die Notwendigkeit eines verantwortungsvollen Umgangs mit der Erde und ihren Ressourcen bewusst zu machen. }\end{array}$ \\
\hline 29.03 .2020 & $\begin{array}{l}\text { Walentin Gorbunow, ehemaliger Vorsitzender der Moskauer Wahlkommission, stirbt im Alter von } 67 \text { Jahren. } \\
\text { Dies gab der Moskauer Bürgermeister Sergej Sobjanin bekannnt. Gorbunow war am 16. März } 2020 \text { aus gesund- } \\
\text { heitlichen Gründen von seinem Posten als Vorsitzender der städtischen Wahlkommission zurückgetreten. Er hatte } \\
\text { die Leitung seit } 1995 \text { inne. }\end{array}$ \\
\hline
\end{tabular}

Die Chronik wird zeitnah erstellt und basiert ausschließlich auf im Internet frei zugänglichen Quellen. Die Redaktion der RusslandAnalysen kann keine Gewähr für die Richtigkeit der Angaben übernehmen.

Zusammengestellt von Alena Schwarz

Sie können die gesamte Chronik seit 1964 auch auf http://www.laender-analysen.de/russland// unter dem Link "Chronik« lesen.

Herausgeber:

Forschungsstelle Osteuropa an der Universität Bremen

Deutsche Gesellschaft für Osteuropakunde e.V.

Deutsches Polen-Institut

Leibniz-Institut für Agrarentwicklung in Transformationsökonomien

Leibniz-Institut für Ost- und Südosteuropaforschung

Zentrum für Osteuropa- und internationale Studien (ZOiS) gGmbH

Redaktion:

Anastasia Stoll (verantwortlich)

Sprachredaktion: Hartmut Schröder

Chronik: Alena Schwarz

Satz: Matthias Neumann

Wissenschaftlicher Beirat:

Dr. Sabine Fischer, Stiftung Wissenschaft und Politik, Berlin

Prof. Dr. Alexander Libman, Universität München

Prof. Dr. Jeronim Perović, Universität Zürich

Dr. Cindy Wittke, Leibniz-Institut für Ost- und Südosteuropaforschung Regensburg

Die Meinungen, die in den Russland-Analysen geäußert werden, geben ausschließlich die Auffassung der Autoren wieder.

Abdruck und sonstige publizistische Nutzung sind nach Rücksprache mit der Redaktion gestattet.

Russland-Analysen-Layout: Cengiz Kibaroglu, Matthias Neumann und Michael Clemens

Alle Ausgaben der Russland-Analysen sind mit Themen- und Autorenindex archiviert unter www.laender-analysen.de

Die Russland-Analysen werden im Rahmen eines Lizenzvertrages in das Internetangebot der Bundeszentrale für politische Bildung (www.bpb.de) aufgenommen.

ISSN 1613-3390 @ 2020 by Forschungsstelle Osteuropa an der Universität Bremen

Forschungsstelle Osteuropa • Länder-Analysen • Klagenfurter Str. 8 • 28359 Bremen • Telefon: + 49 421-218-69600 • Telefax: + 49 421-218-69607

e-mail: laender-analysen@uni-bremen.de•Internet-Adresse: http://www.laender-analysen.de/russland/ 


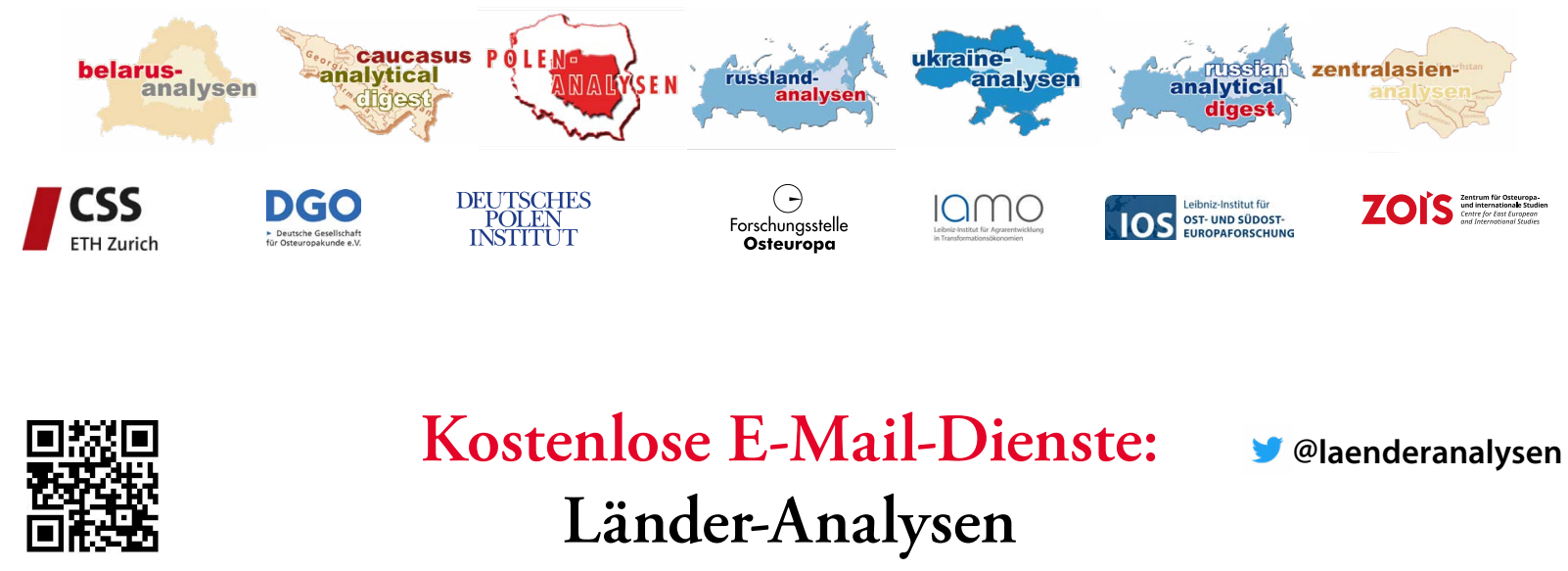

Die Länder-Analysen bieten regelmäßig im kostenlosen Abonnement kompetente Einschätzungen aktueller politischer, wirtschaftlicher, sozialer und kultureller Entwicklungen in Ostmitteleuropa und der GUS. Alle Länder-Analysen verstehen sich als Teil eines gemeinsamen Projektes, das der wissenschaftlich fundierten, allgemeinverständlich formulierten Analyse der Entwicklungen im östlichen Europa, der Offenheit für verschiedene inhaltliche Positionen und der kostenlosen und nicht-kommerziellen Information einer breit verstandenen interessierten Öffentlichkeit verpflichtet ist. Autor/innen sind internationale Fachwissenschaftler/innen und Expert/innen. Die Redaktionen der Länder-Analysen bestehen aus Wissenschaftler/innen mit langjähriger Forschungserfahrung.

Die deutschsprachigen Länder-Analysen werden gemeinsam von der Forschungsstelle Osteuropa an der Universität Bremen, dem Zentrum für Osteuropa- und internationale Studien, der Deutschen Gesellschaft für Osteuropakunde, dem Deutschen Polen-Institut, dem Leibniz-Institut für Agrarentwicklung in Transformationsökonomien und dem Leibniz-Institut für Ost- und Südosteuropaforschung herausgegeben. Die englischsprachigen Länder-Analysen erscheinen in Kooperation der Forschungsstelle Osteuropa mit dem Center for Security Studies (CSS) der ETH Zürich.

Die Länder-Analysen bieten regelmäßig Kurzanalysen zu aktuellen Themen, ergänzt um Grafiken und Tabellen sowie Dokumentationen. Zusätzlich gibt es eine Chronik aktueller Ereignisse.

\section{Belarus-Analysen}

Erscheinungsweise: zweimonatlich

Abonnement unter: http://www.laender-analysen.de/belarus/

\section{Caucasus Analytical Digest}

In englischer Sprache. Erscheinungsweise: zweimonatlich Abonnement unter: http://www.css.ethz.ch/en/publications/cad.html

\section{Polen-Analysen}

Erscheinungsweise: zweimal monatlich

Abonnement unter: http://www.deutsches-polen-institut.de/newsletter/polen-analysen/

\section{Russland-Analysen}

Erscheinungsweise: zweimal monatlich

Abonnement unter: http://www.laender-analysen.de/russland/

\section{Russian Analytical Digest}

In englischer Sprache. Erscheinungsweise: zweimal monatlich Abonnement unter: http://www.css.ethz.ch/en/publications/rad.html

\section{Ukraine-Analysen}

Erscheinungsweise: zweimal monatlich

Abonnement unter: http://www.laender-analysen.de/ukraine/

\section{Zentralasien-Analysen}

Erscheinungsweise: zweimonatlich

Abonnement unter: http://www.laender-analysen.de/zentralasien/ 